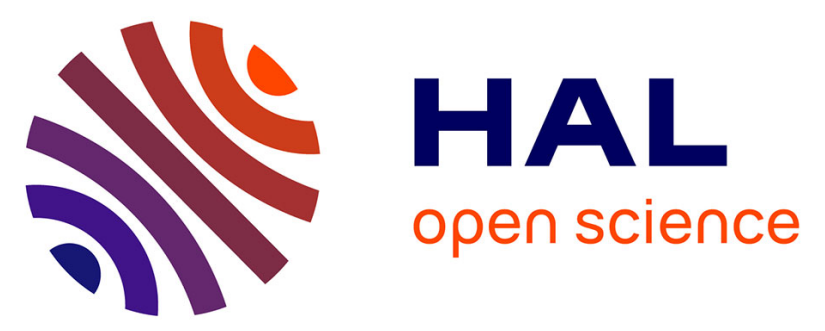

\title{
Cyclopentadienyl Chromium $\beta$-Diketiminate Complexes: Initiators, Ligand Steric Effects, and Deactivation Processes in the Controlled Radical Polymerization of Vinyl Acetate
}

Yohan Champouret, K. Cory Cory Macleod, Ulrich Baisch, Brian O Patrick, Kevin M Smith, Rinaldo Poli

\section{To cite this version:}

Yohan Champouret, K. Cory Cory Macleod, Ulrich Baisch, Brian O Patrick, Kevin M Smith, et al.. Cyclopentadienyl Chromium $\beta$-Diketiminate Complexes: Initiators, Ligand Steric Effects, and Deactivation Processes in the Controlled Radical Polymerization of Vinyl Acetate. Organometallics, 2010, 29 (1), pp.167-176. 10.1021/om900869p . hal-03178932

\author{
HAL Id: hal-03178932 \\ https://hal.science/hal-03178932
}

Submitted on 24 Mar 2021

HAL is a multi-disciplinary open access archive for the deposit and dissemination of scientific research documents, whether they are published or not. The documents may come from teaching and research institutions in France or abroad, or from public or private research centers.
L'archive ouverte pluridisciplinaire HAL, est destinée au dépôt et à la diffusion de documents scientifiques de niveau recherche, publiés ou non, émanant des établissements d'enseignement et de recherche français ou étrangers, des laboratoires publics ou privés. 
Yohan Champouret, ${ }^{\mathrm{a}}$ K. Cory MacLeod, ${ }^{\mathrm{b}}$ Ulrich Baisch, ${ }^{\mathrm{a}}$ Brian O. Patrick, ${ }^{\mathrm{c}}$ Kevin M.

$$
\text { Smith, }{ }^{\mathrm{b} *} \text { Rinaldo } \mathrm{Poli}^{\mathrm{a}, \mathrm{d} *}
$$

${ }^{a}$ CNRS; LCC (Laboratoire de Chimie de Coordination); Université de Toulouse; UPS,

INPT; 205, route de Narbonne, F-31077 Toulouse, France

${ }^{b}$ Department of Chemistry, University of British Columbia Okanagan, 3333

University Way, Kelowna, BC, Canada VIV 1 V7

${ }^{c}$ Department of Chemistry, University of British Columbia, Vancouver, British

Columbia, Canada V6T 1Z1

${ }^{d}$ Institut Universitaire de France, 103, bd Saint-Michel, 75005 Paris, France 


\section{Abstract}

The new compounds $\mathrm{CpCr}\left(\right.$ nacnac $\left.^{\mathrm{Ar}, \mathrm{Ar}}\right)$ with $\operatorname{nacnac}^{\mathrm{Ar}, \mathrm{Ar} \mathbf{r}^{\prime}}=$ $\mathrm{Ar}-\mathrm{N}=\mathrm{C}(\mathrm{Me})=\mathrm{CH}=\mathrm{C}(\mathrm{Me})=\mathrm{N}-\mathrm{Ar} r^{\prime}\left(\mathrm{Ar}=\mathrm{Ar}{ }^{\prime}=\mathrm{C}_{6} \mathrm{H}_{2} \mathrm{Me}_{3}-2,4,6\right.$ or mes, 2; $\mathrm{C}_{6} \mathrm{H}_{3} \mathrm{Et}_{2}-2,6$ or dep, 3; Ar $=\mathrm{C}_{6} \mathrm{H}_{3} \mathrm{Me}_{2}-2,6$ or xyl and Ar' $=\mathrm{C}_{6} \mathrm{H}_{3} i \mathrm{Pr}_{2}-2,6$ or dipp, 4) have been synthesized and used in polymerization experiments in addition to the previously known analogues with $\mathrm{Ar}=\mathrm{Ar}=\mathrm{xyl}, \mathbf{1}$, or dipp, 5. The compounds were used as moderators for the polymerization of vinyl acetate (VAc) initiated by V-70, according to an OMRP mechanism. The alkylchromium(III) thermal initiator $\mathrm{CpCr}\left(\right.$ nacnac $\left.^{\mathrm{xyl}, \mathrm{xyl}}\right)\left(\mathrm{CH}_{2} \mathrm{CMe}_{3}\right)(\mathbf{8})$ was synthesized from $\mathrm{CpCr}\left(\operatorname{nacnac}^{\mathrm{xyl}, \mathrm{xyl}}\right)(\mathrm{OTs})$ (7) and $\mathrm{Mg}\left(\mathrm{CH}_{2} \mathrm{CMe}_{3}\right)_{2}$ (dioxane), while 7 was obtained from $\mathrm{CpCr}\left(\operatorname{nacnac}^{\mathrm{xyl}, \mathrm{xyl}}\right) \mathrm{Cl}(\mathbf{6})$ and AgOTs. The polymerizations carried out with (1-5)/V-70/VAc at elevated temperatures yielded rapid deactivation, suggestive of irreversible radical trapping. On the other hand, room temperature polymerizations carried out with 6/VAc proceeded, albeit slowly, to greater conversions. A labilizing effect of the Ar/Ar' steric bulk is suggested by QM/MM calculations of $\mathrm{Cr}^{\mathrm{III}}-\mathrm{C}$ BDE for models of the OMRP dormant species with 1, 5, and the parent system where $\mathrm{Ar}=\mathrm{Ar} \mathbf{r}^{\prime}=\mathrm{Ph}$. Thermal deactivation of the nacnac ${ }^{\mathrm{xyl}, \mathrm{xyl}}$ system has been evidenced, with formation of the acetate complex $\mathrm{CpCr}\left(\operatorname{nacnac}^{\mathrm{xyl}, \mathrm{xyl}}\right)(\mathrm{OAc}), \mathbf{9}$, as confirmed by an UV-vis study and by independent synthesis. This product is proposed to form by $\beta$-acetate transfer from the growing radical chain, triggered by a head-head monomer insertion. Compounds 2, 3, 6, 7, 8 and 9 have been structurally characterized by X-ray diffraction methods. 


\section{Introduction}

The controlled polymerization of functionalized monomers like vinyl acetate continues to pose a formidable challenge to transition metal chemists. Early metal catalysts that effectively polymerize non-polar monomers by an insertion mechanism are incompatible with vinyl ester substrates. ${ }^{1}$ More functional group tolerant late metal catalysts experience problems for copolymerization of vinyl acetate and ethylene due to low $\pi$-bonding affinity, chelate formation, and $\beta$-acetate elimination. $^{2-4}$ Vinyl acetate is also a difficult monomer for controlled radical polymerization methods due to the relatively high reactivity of the propagating radical species compared to more tractable substrates such as styrene or methyl acrylate. ${ }^{5}$

Organometallic radical polymerization (OMRP) provides a new route to poly(vinylacetate). In the OMRP mechanism, unwanted bimolecular radical coupling reactions are effectively prevented by reversible formation and homolytic cleavage of metal-alkyl bonds. ${ }^{6}$ Cobalt-mediated radical polymerization is the most well explored system for OMRP of vinyl acetate. The mechanistic details of these polymerizations are rather complex, with a range of termination and chain transfer steps playing a role dictated by the degree of solvent coordination and the spin state of the $\mathrm{Co}$ (II) and Co(III) intermediate species. ${ }^{7}$

In principle, well-defined high spin $\mathrm{Cr}^{\mathrm{II}}$ and $\mathrm{Cr}^{\mathrm{III}}$ complexes could serve as a simpler system for preparing poly(vinylacetate) via OMRP. Chromium(II) species such as aqueous $\left[\mathrm{Cr}\left(\mathrm{H}_{2} \mathrm{O}\right)_{6}\right]^{2+}$ or $\mathrm{CrCl}_{2}$ in coordinating aprotic solvents have long been known to effectively trap organic radicals at close to diffusion controlled rates to 
form $\mathrm{Cr}^{\mathrm{III}}$-alkyl intermediates. ${ }^{8}$ This fundamental reactivity mode is the key step in the chromium-mediated coupling of organic halides and aldehydes. ${ }^{9,} 10$ The homolytic bond dissociation energy (BDE) of a $\mathrm{Cr}^{\mathrm{III}}$-alkyl bond is typically greater than that of a

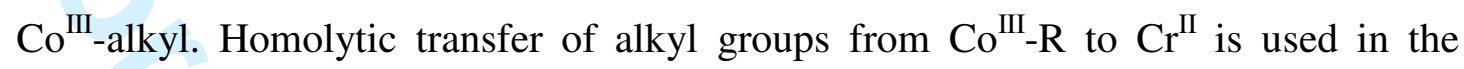
Takai-Utimoto reaction where catalytic amounts of $\mathrm{B}_{12}$ or cobalt phthalocyanine are used to activate alkyl halides and transfer the organic radical from $\mathrm{Co}$ to $\mathrm{Cr}$ prior to coupling with aldehydes. ${ }^{11}$ While the trapping of organic radicals with $\mathrm{Cr}^{\mathrm{II}}$ to form octahedral $\mathrm{Cr}^{\mathrm{III}}$ organometallic species is usually considered to be rapid and irreversible, the reaction can be reversible for secondary or tertiary radicals due to the lowering of the Cr-R BDE through adverse steric interactions. ${ }^{12,13}$

CpCr(nacnac) complexes are high spin, well characterized species that do not bind coordinating solvents but have been shown to trap $\mathrm{CH}_{3}$ radicals. ${ }^{14,} 15$ $\mathrm{CpCr}($ nacnac $)\left(\mathrm{CH}_{3}\right)$ complexes can be independently synthesized by the reaction of Grignard reagents with the corresponding $\mathrm{Cr}^{\mathrm{III}}$ triflate or halide compounds. Modifying the size of the ortho substituents of the nacnac N-aryl groups should exert a dramatic influence on the $\mathrm{Cr}^{\mathrm{III}}-\mathrm{R}$ BDE for $\mathrm{CpCr}($ nacnac) $\mathrm{R}$ complexes, as indicated by preliminary DFT calculation. ${ }^{16}$ This desired tunability of the M-R BDE is critical for both exploring structure-activity relationships for these reagents and for developing a class of well-defined organometallic complexes capable of mediating OMRP reactions for a range of activated olefin substrates. ${ }^{6}$

In 2008, we communicated our preliminary studies towards OMRP of vinyl acetate using $\mathrm{CpCr}\left(\right.$ nacnac) complexes and $\mathrm{V}-70 .{ }^{16}$ In this paper, we further examine 
the structure-activity relationships of vinyl acetate polymerization using isolated $\mathrm{CpCr}$ (nacnac) compounds with V-70. Although the paramagnetic nature of the Cr ${ }^{\mathrm{II}}$ and $\mathrm{Cr}^{\mathrm{III}}$ complexes makes interpretation of their NMR spectra difficult, the UV-vis spectra of these intensely coloured species proved to be quite informative. Employing elevated temperatures to accelerate initiation in the $\mathrm{CpCr}$ (nacnac)/V-70/vinyl acetate system unexpectedly led to a decrease in the observed rate of polymerization due to formation of an inactive $\mathrm{Cr}^{\mathrm{III}}$ acetate thermal decomposition product. As an alternative to thermolysis of $\mathrm{CpCr}$ (nacnac) with $\mathrm{V}-70$, a well-defined $\mathrm{Cr}^{\mathrm{III}}$ neopentyl complex was developed as a single-component OMRP reagent. The choice of the neopentyl group was based on the high steric demand of this specific alkyl ligand, which has long been used to provoke unique organometallic reactivity, both of non-radical ${ }^{17-20}$ and of radical type. ${ }^{21-23}$ 


\section{Experimental Section}

Materials. All reactions, unless otherwise stated, were carried out under dry, oxygen-free argon or nitrogen, using standard Schlenk and glove box techniques. Solvents were dried by using the method of Grubbs ${ }^{24}$ or they were distilled under argon from appropriate drying agents and degassed by three freeze-vacuum-thaw cycles prior to use. ${ }^{25}$ Celite (Aldrich) was dried overnight at $110^{\circ} \mathrm{C}$ before being evacuated and then stored under argon or nitrogen. Vinyl acetate (VAc, $99 \%$, Alfa Aesar or 99+\%, Aldrich) was passed through a neutral alumina column to remove the stabilizer, dried over calcium hydride, distilled at $90{ }^{\circ} \mathrm{C}$, degassed by three freeze-vacuum-thaw cycles and stored under argon or nitrogen at $-20{ }^{\circ} \mathrm{C}$. 2,2'-azobis(4-methoxy-2,4-dimethylvaleronitrile) (V-70, 96\%, Wako) was used as received. $n$-BuLi (1.6 M in hexanes), p-toluenesulfonic acid monohydrate, acetylacetonate, 2,6-dimethylaniline, 2,6-diisopropylaniline, 2,6-diethylaniline, 2,4,6-trimethylaniline, $\mathrm{CrCl}_{3}$ (anhydrous), 1,4-dioxane, silver $p$-toluenesulfonate and silver acetate were purchased from Aldrich and used as received. The symmetric $\beta$-diketiminato ligands, $\left(2,6-\mathrm{Me}_{2} \mathrm{C}_{6} \mathrm{H}_{3}\right) \mathrm{NHC}(\mathrm{Me})-$ $\mathrm{CHC}(\mathrm{Me}) \mathrm{N}\left(2,6-\mathrm{Me}_{2} \mathrm{C}_{6} \mathrm{H}_{3}\right),{ }^{26} \quad\left(2,6-\mathrm{Et}_{2} \mathrm{C}_{6} \mathrm{H}_{3}\right) \mathrm{NHC}(\mathrm{Me}) \mathrm{CHC}(\mathrm{Me}) \mathrm{N}\left(2,6-\mathrm{Et}_{2} \mathrm{C}_{6} \mathrm{H}_{3}\right),{ }^{27}$ $\left(2,4,6-\mathrm{Me}_{3} \mathrm{C}_{6} \mathrm{H}_{2}\right) \mathrm{NHC}(\mathrm{Me}) \mathrm{CHC}(\mathrm{Me}) \mathrm{N}\left(2,4,6-\mathrm{Me}_{3} \mathrm{C}_{6} \mathrm{H}_{2}\right)^{27}$ and the mixed $\mathrm{N}$-aryl $\beta$-diketiminato ligand, $\left(2,6-i \mathrm{Pr}_{2} \mathrm{C}_{6} \mathrm{H}_{3}\right) \mathrm{NHC}(\mathrm{Me}) \mathrm{CHC}(\mathrm{Me}) \mathrm{N}\left(2,6-\mathrm{Me}_{2} \mathrm{C}_{6} \mathrm{H}_{3}\right)^{28}$ were prepared according to the literature procedure. $\mathrm{NaCp}$ was prepared according to the literature procedure, ${ }^{29}$ or was purchased from Aldrich as a $2.0 \mathrm{M}$ solution in THF and 
used as received. Compounds $\mathrm{Mg}\left(\mathrm{CH}_{2} \mathrm{CMe}_{3}\right)_{2} \cdot x(1,4 \text {-dioxane })^{30} \mathrm{CrCl}_{2}$ (tmeda), ${ }^{31} \mathbf{1}^{16}$ and $\mathbf{5}^{16}$ were prepared according to literature procedures.

Characterizations. ${ }^{1} \mathrm{H}$ NMR spectra were recorded on a Bruker ARX 250 or a Bruker DPX 300 spectrometer. A Varian Cary 100 Bio UV-visible spectrophotometer was used to conduct measurements using a specially constructed cell for air-sensitive samples: a Kontes Hi-Vac Valve with PTFE plug was attached by a professional glassblower to a Hellma $10 \mathrm{~mm}$ path length quartz absorption cell with a quartz-to-glass graded seal. Size exclusion chromatography (SEC) of poly (vinyl acetate) was carried out in filtered THF (flow rate: $1 \mathrm{ml} / \mathrm{min}$ ) at $35^{\circ} \mathrm{C}$ on a $300 \times 7,5$ mm PL gel 5micrometer mixed-D column (polymer laboratories), equipped with multiangle light scattering (minidawn Tristar, Wyatt Technology Corporation) and refractive index (RI2000, Sopares) detectors, with a waters column pack (300x7,5 mm, ultrastyragel 104,103,100 ̊), equipped with multiangle light scattering (miniDawn Tristar,Wyatt Technology Corp.) and refractive index (waters 410) detectors or at $30^{\circ} \mathrm{C}$ on a Polymer Labs PL-GPC 50 plus (two PLgel mixC columns in series) with a PL-AS RT autosampler and PL-RI detector. The isolated polymer samples were dissolved in THF and the polymer solutions were filtered (pore size $=0.45 \mu \mathrm{m}$ ) before chromatographic analysis. The columns were calibrated against linear polystyrene standards (Polymer Laboratories). Elemental analyses were performed by Guelph Chemical Laboratories, Guelph, ON, Canada. Solution magnetic susceptibilites were determined by the Evans method. ${ }^{32}$

Synthesis of $\mathbf{C p C r}\left(\right.$ nacnac $\left.^{\text {mes,mes }}\right)$ (2): Following a procedure similar to that 
previously reported for compound $1,{ }^{16}$ compound $\left(2,4,6-\mathrm{Me}_{3} \mathrm{C}_{6} \mathrm{H}_{2}\right) \mathrm{NHC}(\mathrm{Me})-$ $\mathrm{CHC}(\mathrm{Me}) \mathrm{N}\left(2,4,6-\mathrm{Me}_{3} \mathrm{C}_{6} \mathrm{H}_{2}\right)(744 \mathrm{mg}, 2.23 \mathrm{mmol})$ was dissolved in THF (12 mL). $n$-BuLi (1.60 mL, $2.56 \mathrm{mmol}, 1.15$ equiv) was added dropwise and the resulting yellow solution was stirred for $30 \mathrm{~min}$ at room temperature. In a separate Schlenk flask, $\mathrm{CrCl}_{2}$ (tmeda) (531 mg, $2.22 \mathrm{mmol}, 1$ equiv) was suspended in THF (35 mL) followed by the addition of $\mathrm{NaCp}(1.25 \mathrm{~mL}, 2.50 \mathrm{mmol}, 1.13$ equiv $)$. The resulting mixture was stirred for $30 \mathrm{~min}$ at room temperature. To this solution, the lithium salt prepared above was added dropwise and the mixture was stirred at room temperature overnight. The solvent was evaporated in vacuo and the residue was extracted with hexanes, followed by filtration through Celite. The solvent was again removed in vacuo and the complex was dissolved in hexanes $(20 \mathrm{~mL})$, filtered and cooled to $-35^{\circ} \mathrm{C}$ for several days. $730 \mathrm{mg}$ of black crystals were isolated in two crops. Yield: 73\%. $\mu_{\text {eff }}\left(\right.$ Evans, $\left.\mathrm{C}_{6} \mathrm{D}_{6}\right)$ 4.8(1) $\mu_{\mathrm{B}}$. Anal. Calcd. for $\mathrm{C}_{28} \mathrm{H}_{34} \mathrm{CrN}_{2}$ : C, 74.64; H, 7.61; $\mathrm{N}$, 6.22. Found: C, 74.83; H, 7.96; N, 6.42. UV/Vis (hexanes; $\lambda_{\max }, \mathrm{nm}(\varepsilon$, $\left.\left.\mathrm{M}^{-1} \mathrm{~cm}^{-1}\right)\right): 308$ (11700), 427 (7210), 573 (376).

Synthesis of $\mathrm{CpCr}\left(\right.$ nacnac $\left.^{\text {dep,dep}}\right)$ (3): Following a procedure similar to that previously reported for compounds $\mathbf{1},{ }^{16}$ compound $\left(2,6-\mathrm{Et}_{2} \mathrm{C}_{6} \mathrm{H}_{3}\right) \mathrm{NHC}(\mathrm{Me})$ $\mathrm{CHC}(\mathrm{Me}) \mathrm{N}\left(2,6-\mathrm{Et}_{2} \mathrm{C}_{6} \mathrm{H}_{3}\right)(1.00 \mathrm{~g}, 2.76 \mathrm{mmol})$ was dissolved in THF $(10 \mathrm{~mL})$ and cooled to $-40{ }^{\circ} \mathrm{C}$ in an acetonitrile/liquid nitrogen bath. $n$-BuLi $(1.75 \mathrm{~mL}, 2.80 \mathrm{mmol}$, 1.01 equiv) was added dropwise and the resulting yellow solution was stirred for one hour at $-40^{\circ} \mathrm{C}$. In a separate Schlenk flask, $\mathrm{CrCl}_{2}$ (tmeda) $(660 \mathrm{mg}, 2.76 \mathrm{mmol}, 1$ equiv) and $\mathrm{NaCp}$ (243 mg, $2.76 \mathrm{mmol}, 1$ equiv) were suspended in THF (15 mL) and the 
contents stirred for $20 \mathrm{~min}$ at room temperature. To this solution, the lithium salt prepared above was added dropwise via a cannula and the mixture was stirred at room temperature overnight. The solvent was evaporated in vacuo and the residue was extracted with pentane, followed by filtration through Celite. The solvent was again removed in vacuo and the complex was dissolved in the minimum amount of pentane, filtered and cooled to $-80^{\circ} \mathrm{C}$ overnight to yield $462 \mathrm{mg}$ of black crystals. Yield: $35 \%$. $\mu_{\text {eff }}\left(\right.$ Evans, $\left.\mathrm{C}_{6} \mathrm{D}_{6}\right)$ 4.6(1) $\mu_{\mathrm{B}}$. Anal. Calcd. for $\mathrm{C}_{30} \mathrm{H}_{38} \mathrm{CrN}_{2}$ : C, 75.28; H, 8.00; N, 5.85. Found: C, 74.97; H, 8.30; N, 5.96. UV/Vis (hexanes; $\left.\lambda_{\max }, \mathrm{nm}\left(\varepsilon, \mathrm{M}^{-1} \mathrm{~cm}^{-1}\right)\right): 308$ (12200), 428 (7910), $576(411)$.

Synthesis of $\operatorname{CpCr}\left(\right.$ nacnac $\left.^{\text {xyl,dipp }}\right)$ (4). Using a procedure identical to that described above for compound 2, compound $\operatorname{CpCr}\left(\right.$ nacnac $\left.^{\text {xyl,dipp }}\right)(\mathbf{4}, 223 \mathrm{mg})$ was obtained as black crystals from $\left(2,6-i \mathrm{Pr}_{2} \mathrm{C}_{6} \mathrm{H}_{3}\right) \mathrm{NHC}(\mathrm{Me}) \mathrm{CHC}(\mathrm{Me}) \mathrm{N}\left(2,6-\mathrm{Me}_{2} \mathrm{C}_{6} \mathrm{H}_{3}\right)$ (316 mg, $0.872 \mathrm{mmol}$ ). Yield: 54\%. $\mu_{\mathrm{eff}}$ (Evans, $\left.\mathrm{C}_{6} \mathrm{D}_{6}\right)$ 4.4(1) $\mu_{\mathrm{B}}$. Anal. Calcd for $\mathrm{C}_{30} \mathrm{H}_{38} \mathrm{CrN}_{2}$ : C, 75.28; H, 8.00; N, 5.85. Found: C, 75.00; H, 8.38; N, 5.62.

Synthesis of $\mathbf{C p C r}\left(\right.$ nacnac $\left.^{\mathrm{xyl}, \mathrm{xyl}}\right) \mathbf{C l}(6)$. Compound (2,6- $\left.\mathrm{Me}_{2} \mathrm{C}_{6} \mathrm{H}_{3}\right) \mathrm{NHC}(\mathrm{Me})-$ $\mathrm{CHC}(\mathrm{Me}) \mathrm{N}\left(2,6-\mathrm{Me}_{2} \mathrm{C}_{6} \mathrm{H}_{3}\right)(1.43 \mathrm{~g}, 4.67 \mathrm{mmol})$ was added to a Schlenk flask and dissolved in THF $(30 \mathrm{~mL})$ and cooled to $0^{\circ} \mathrm{C}$ in an ice-water bath. $n$-BuLi $(3.20 \mathrm{~mL}$, $5.12 \mathrm{mmol}, 1.10$ equiv) was added dropwise and the resulting yellow solution was allowed to warm to room temperature while stirring for 1 hour. The lithium salt was then cannulated into a suspension of $\mathrm{CrCl}_{3}$ (744 mg, $4.70 \mathrm{mmol}, 1.00$ equiv) in THF (20 $\mathrm{mL})$ and stirred at room temperature overnight. $\mathrm{NaCp}(2.60 \mathrm{~mL}, 5.20 \mathrm{mmol}, 1.11$ equiv) was added to the solution which was again stirred at room temperature 
overnight. The solvent was evaporated in vacuo and the residue was extracted with 40 $\mathrm{mL}$ of a hexanes/dichloromethane mixture (3:1), filtered through Celite and rinsed with hexanes $(3 \times 5 \mathrm{~mL})$. The green to incident and orange to transmitted light filtrate was concentrated and cooled to $-20^{\circ} \mathrm{C}$ to yield $1.66 \mathrm{~g}$ of dark green crystals over several days in three crops. Yield: 78\%. Anal. Calcd. for $\mathrm{C}_{26} \mathrm{H}_{30} \mathrm{CrN}_{2} \mathrm{Cl}$ : C, 68.19; H, 6.60; $\mathrm{N}, 6.12$. Found: $\mathrm{C}, 67.88 ; \mathrm{H}, 6.50 ; \mathrm{N}, 5.73$. UV/Vis (hexanes; $\lambda_{\max }, \mathrm{nm}\left(\varepsilon, \mathrm{M}^{-1} \mathrm{~cm}^{-1}\right)$ ): 418 (7220), 581 (504).

Synthesis of $\mathbf{C p C r}\left(\right.$ nacnac $\left.^{\mathrm{xyl}, \mathrm{xyl}}\right)$ OTs (7). Compound 6 (1.28 g, $\left.2.79 \mathrm{mmol}\right)$ and AgOTs (781 mg, $2.80 \mathrm{mmol}, 1.00$ equiv) were placed in a Schlenk flask followed by the addition of THF $(60 \mathrm{~mL})$. The mixture was stirred overnight at room temperature, filtered through Celite and the solvent was evaporated in vacuo. The residue was extracted with $32 \mathrm{~mL}$ of a hexanes/dichloromethane mixture (4:1), filtered through Celite and rinsed with hexanes $(2 \times 5 \mathrm{~mL})$. The green to incident and orange to transmitted light filtrate was cooled to $-20^{\circ} \mathrm{C}$ to yield $1.40 \mathrm{~g}$ of black crystals over several days in four crops. Yield: $84 \%$. Anal. Calcd. for $\mathrm{C}_{33} \mathrm{H}_{37} \mathrm{CrO}_{3} \mathrm{~N}_{2} \mathrm{~S}: \mathrm{C}, 66.76 ; \mathrm{H}$, 6.28; N, 4.72. Found: C, 66.50; H, 6.20; N, 4.34. UV/Vis (diethyl ether; $\lambda_{\max }, \mathrm{nm}(\varepsilon$, $\left.\left.\mathrm{M}^{-1} \mathrm{~cm}^{-1}\right)\right): 411(8140), 571(548)$.

Synthesis of $\mathbf{C p C r}\left(\right.$ nacnac $\left.^{\mathrm{xyl}, \mathrm{xyl}}\right) \mathbf{C H}_{2} \mathrm{CMe}_{3}$ (8). Compound 7 (600 mg, 1.01 mmol) was added to a Schlenk flask followed by the addition of diethyl ether (30 mL). $\mathrm{Mg}\left(\mathrm{CH}_{2} \mathrm{CMe}_{3}\right)_{2} \cdot 1.05$ (1,4-dioxane) (143 mg, $0.554 \mathrm{mmol}, 0.549$ equiv) in diethyl ether ( $5 \mathrm{~mL}$ ) was added dropwise to the Schlenk. The mixture was stirred for $1.5 \mathrm{~h}$ at room temperature, the solvent was evacuated in vacuo and the residue was extracted with 
hexanes $(30 \mathrm{~mL})$, filtered through Celite and rinsed with hexanes $(3 \times 5 \mathrm{~mL})$. The solvent was again evacuated in vacuo and the residue was extracted with hexanes (15 $\mathrm{mL}$ ), filtered and cooled to $-35^{\circ} \mathrm{C}$ to yield $335 \mathrm{mg}$ of black crystals over several days in four crops. Yield: $67 \%$. Anal. Calcd. for $\mathrm{C}_{31} \mathrm{H}_{41} \mathrm{CrN}_{2}$ : C, 75.42; H, 8.37; N, 5.67. Found: C, 75.27; H, 8.69; N, 5.66. UV/Vis (hexanes; $\left.\lambda_{\max }, \mathrm{nm}\left(\varepsilon, \mathrm{M}^{-1} \mathrm{~cm}^{-1}\right)\right): 404$ (5170), 567 (1050).

Synthesis of $\mathbf{C p C r}\left(\operatorname{nacnac}^{\mathrm{xyl}, \mathrm{xyl}}\right) \mathbf{O C}(\mathbf{O}) \mathbf{M e}(9)$. Compound 7 (259 mg, 0.566 mmol) and AgOAc (95.2 mg, 0,570 mmol, 1.01 equiv) were place in a Schlenk flask followed by the addition of THF $(20 \mathrm{~mL})$. The mixture was stirred overnight at room temperature in the absence of light, the solvent was evacuated in vacuo and the residue was extracted with $12 \mathrm{~mL}$ of a hexanes/dichloromethane mixture (3:1), filtered through Celite and rinsed with hexanes $(3 \times 3 \mathrm{~mL})$. The green filtrate was concentrated slightly and cooled to $-20^{\circ} \mathrm{C}$ to yield $187 \mathrm{mg}$ of black crystals over several days in three crops. Yield: $69 \%$. UV/Vis (hexanes; $\left.\lambda_{\max }, \mathrm{nm}\left(\varepsilon, \mathrm{M}^{-1} \mathrm{~cm}^{-1}\right)\right): 411$ (9160), 508 (446), 588 (574).

General procedures for the radical polymerization of vinyl acetate. (a) OMRP procedure: $\mathrm{Cr}^{\mathrm{II}}+\mathrm{V}-\mathbf{7 0}$. All polymerisations were conducted following the same experimental protocol. A typical experiment is described here as a representative example with complex $4(\mathrm{Cr}: \mathrm{V}-70: \mathrm{VAc}=1: 0.8: 500)$. All operations were carried out under a protective argon atmosphere. Complex 4 (41 mg, $0.086 \mathrm{mmol}, 1$ equiv) and V-70 (18.7 mg $0.061 \mathrm{mmol}, 0.8$ equiv) were introduced in a Schlenk tube, followed by the addition of degassed vinyl acetate ( $4 \mathrm{~mL}, 43 \mathrm{mmol}, 500$ equiv). The Schlenk 
tube was degassed by three freeze-vacuum-thaw cycles and then immersed in an oil bath preheated at $50^{\circ} \mathrm{C}$. At the desired time, the Schlenk flask was rapidly cooled to room temperature by immersion into iced water before sample withdrawal. The monomer conversion was determined gravimetrically after removal of the unconverted monomer under reduced pressure and the resulting residue was used for SEC characterization.

(b) OMRP procedure: $\mathbf{C r}^{\mathrm{III}}-\mathbf{N p}$. The experimental protocol is similar to that described above for the OMRP procedure: $\mathrm{Cr}^{\mathrm{II}}+\mathrm{V}-70$. As an example, complex 8 (17.5 mg, $0.035 \mathrm{mmol}, 1$ equiv) and VAc (4 mL, $43 \mathrm{mmol}, 1200$ equiv) were introduced into a Schlenk flask and stirred at room temperature. At the desired time, a sample was removed from the Schlenk flask and analyzed as described above.

X-ray crystallography. A single crystal of each compound was mounted on a glass fiber and centered on the optical path of a Bruker X8 APEX II diffractometer with graphite monochromated Mo-K $\alpha$ radiation. The data were collected at a temperature of $-100.0 \pm 0.1^{\circ} \mathrm{C}$ in a series of $\phi$ and $\omega$ scans in $0.50^{\circ}$ oscillations. Data were collected and integrated using the Bruker SAINT software package ${ }^{33}$ and were corrected for absorption effects using the multi-scan technique (SADABS), ${ }^{34}$ and for Lorentz and polarization effects. All structures were solved by direct methods with SIR97. ${ }^{35}$ For structures $\mathbf{2}, \mathbf{3}$ and $\mathbf{6}$ the $\mathrm{Cp}$ ring was found disordered among different orientations (four for $\mathbf{2}$ and two for $\mathbf{3}$ and 6). Two of the four orientations in $\mathbf{2}$ are symmetry-related to the other two since the molecule sits on a twofold axis with half molecule in the asymmetric unit. Refinement of the population of each of these 
fragments resulted in near equivalent values of 0.25 . For compounds 3 and $\mathbf{6}$, the two $\mathrm{Cp}$ orientations had equal population. In addition, one disordered half-molecule of hexane is present in the asymmetric unit of 6 . This disorder was modeled in two orientations, with restraints employed to maintain similar geometries. Compound $\mathbf{8}$ crystallizes with two independent molecules in the asymmetric unit. Compound $\mathbf{9}$ crystallizes as a two-component split crystal with the two components related by a $51^{\circ}$ rotation about the $\left(\begin{array}{lll}0 & 0 & 1\end{array}\right)$ real axis. Data were integrated for both twin components, including both overlapping and non-overlapping reflections. The structure was solved using non-overlapped data from the major twin component. Subsequent refinements of 9 were carried out using HKLF 5 format data set containing complete from component 2 and all overlapped reflections from component 1 . The batch scale refinement showed a roughly 53:47 ratio between the major and minor twin components. All non-hydrogen atoms (except those of the $\mathrm{Cp}$ ring for compound 2 and the disorder solvent atoms for $\mathbf{6}$ ) were refined anisotropically. All hydrogen atoms were placed in calculated positions but were not refined. All refinements were performed using the SHELXTL crystallographic software package of Bruker-AXS. ${ }^{36}$ The molecular drawings were generated by the use of ORTEP- $3^{37}$ and POV-Ray. Crystal data and structure refinement parameters are collected in the Supporting Information.

Computational details. QM/MM calculations were carried out by use of the Gaussian03 suite of programs ${ }^{38}$ with use of the B3LYPfunctional ${ }^{39}$ within the DFT methodology for the QM part and of the $\mathrm{UFF}^{40}$ for the MM part. The basis set 
chosen for the QM calculations comprised the 6-31G* set for the $\mathrm{C}, \mathrm{N}$ and $\mathrm{O}$ atoms, the $6-31 \mathrm{G}^{* *}$ set for the $\mathrm{H}$ atoms, and the SDD set, which includes a pseudopotential, augmented by an $\mathrm{f}$ polarization function with the optimized ${ }^{41} 1.941$ coefficient for the $\mathrm{Cr}$ atom. The cutoff between the QM and MM parts was placed at the level of the Ar- $\mathrm{N}$ bonds, with the $\mathrm{N}=\mathrm{C}(\mathrm{Me})-\mathrm{CH}-\mathrm{C}(\mathrm{Me})=\mathrm{N}$ diketiminato moiety being treated quantomechanically together with the $\mathrm{Cr}$ atom, the $\mathrm{Cp}$ ring, and the $\mathrm{CH}(\mathrm{OAc}) \mathrm{CH}_{3}$ ligand, while the entire aryl substituents were handled at the MM level. The input geometries were obtained or adapted from the crystallographically characterized compounds. Spin contamination was negligible, all calculations converging with $\left\langle\mathrm{S}^{2}\right\rangle$ close to the expected values ( 6 for the quintet state of $\mathrm{Cr}^{\mathrm{II}}-6.022$ for all three compounds; 3.75 for the quartet state of $\mathrm{Cr}^{\mathrm{III}}-3.824$ for the Dipp derivative). The values reported are the electronic energies without ZPVE correction. 


\section{Results and Discussion}

\section{(a) Syntheses and characterization of $\mathrm{CpCr}^{\mathrm{II}}$ (nacnac)}

The $\mathrm{CpCr}^{\mathrm{II}}$ (nacnac) compounds used in this study are shown in Scheme 1 (xyl = 2,6-dimethylphenyl; mes = 2,4,6-trimethylphenyl; dep = 2,6-diethylphenyl; dipp = 2,6-diisopropylphenyl). Of these, only compounds $\mathbf{1}^{16}$ and $\mathbf{5}^{14,16}$ have previously been described in the literature.

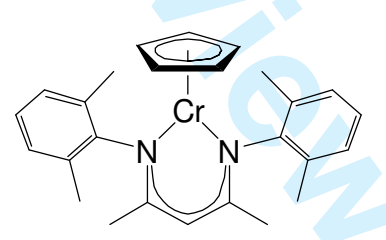

1

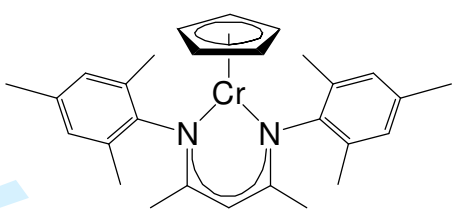

2

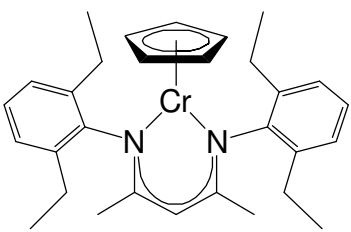

3

CpCr(nacnac dep,dep)

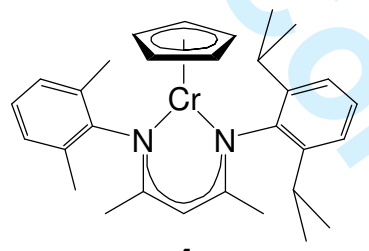

4

$\operatorname{CpCr}\left(\right.$ nacnac $\left.^{\text {xyl,dipp }}\right)$

$\mathrm{CpCr}\left(\right.$ nacnac $\left.^{\text {mes,mes}}\right)$

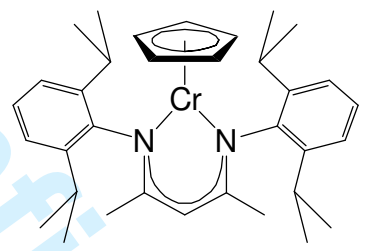

5

$\mathrm{CpCr}\left(\right.$ nacnac $\left.^{\text {dipp,dipp }}\right)$

\section{Scheme 1}

The new $\mathrm{CpCr}^{\mathrm{II}}$ (nacnac) complexes (2-4) were prepared following the literature procedure reported for $\mathbf{1},{ }^{14,16}$ which consists of the one-pot reaction of $\mathrm{CrCl}_{2}$ (tmeda) with one equivalent of $\mathrm{NaCp}$, followed by one equivalent of the appropriate nacnacLi salt (Scheme 2). Compounds $\mathbf{1 - 5}$ are highly air sensitive. The ${ }^{1} \mathrm{H}$ NMR spectra of compounds 2-4 in $\mathrm{C}_{6} \mathrm{D}_{6}$ all displayed multiple broad, overlapping, unassignable signals between 0 and $13 \mathrm{ppm}$. The magnetic susceptibilities of complexes 2-4 were determined using the Evans method, ${ }^{32}$ and were consistent with the high spin $\mathrm{Cr}^{\mathrm{II}}$ 
configuration previously determined for $\mathbf{1}^{14}$ As previously reported for compound $\mathbf{5},{ }^{14}$ solutions of the $\mathrm{Cr}^{\mathrm{II}}$ complexes $\mathbf{1 - 4}$ are green to incident light with a distinctive magenta color to transmitted light. They exhibit two very strong bands at 307-308 $\mathrm{nm}$ and $427-430 \mathrm{~nm}$, comparable to those observed for three coordinate $\mathrm{Cr}^{\mathrm{II}}$ nacnac alkyl complexes. ${ }^{42}$ Compounds 1-5 also have a less intense single band at 558-576 nm.

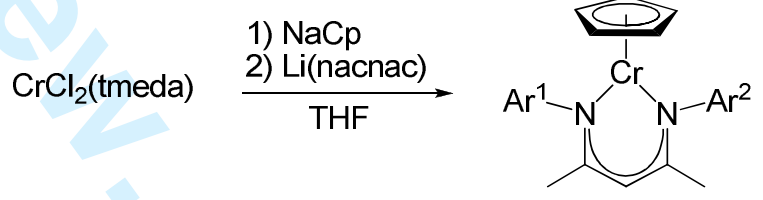

\section{Scheme 2}

Compounds $\mathbf{2}$ and $\mathbf{3}$ have also been characterized by single crystal X-ray diffraction. The geometry of the two $\mathrm{Cr}^{\mathrm{II}}$ compounds (Figure 1) can be described as a "two-legged piano stool", with the Cp ring centroid lying close to the plane defined by the $\mathrm{Cr} 1, \mathrm{~N} 1$ and $\mathrm{N} 2$ or $\mathrm{N} 1 *$ atoms. Relevant bond distances and angles are collected in Table 1. The bonding parameters for compounds $\mathbf{2}$ and $\mathbf{3}$ are very similar to those found in previously reported structures for $\mathrm{CpCr}$ (nacnac) $\mathrm{Cr}^{\mathrm{II}}$ complexes. ${ }^{14,16}$ 
(a)

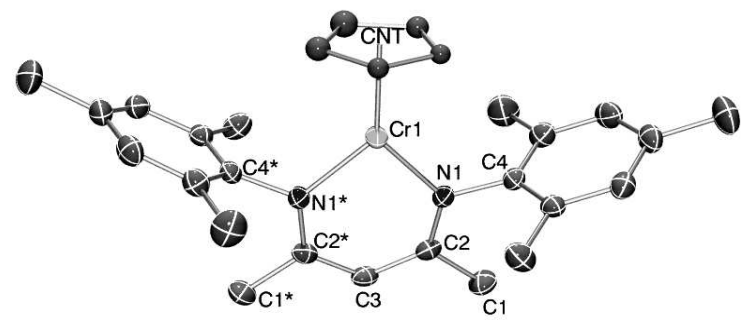

(b)

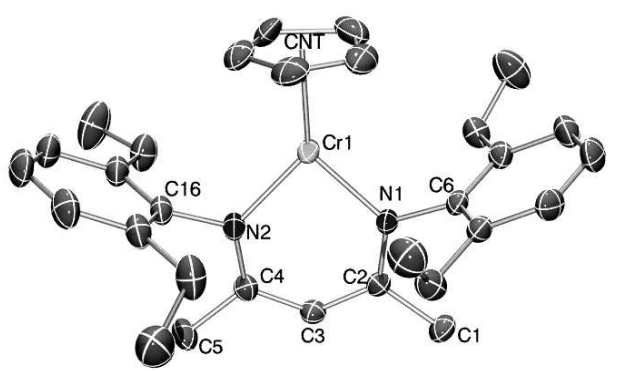

Figure 1. Views of compounds $\mathbf{2}$ (a) and $\mathbf{3}$ (b), with thermal ellipsoids drawn at the $50 \%$ probability level. All $\mathrm{H}$ atoms are omitted and only one $\mathrm{Cp}$ orientation is shown for clarity.

Table 1. Selected bond distances $(\AA)$ and angles $\left(^{\circ}\right)$ for compounds 2 and $\mathbf{3}$.

2

3

Distances

CNT-Cr

2.013(12)

$\mathrm{Cr}-\mathrm{N}$

$2.007(2)$

$2.0276(12)$

Cr-N

$2.0260(12)$

Angles

CNT-Cr-N

$134.0(3)$

$134.8(3)$

CNT-Cr-N

$\mathrm{CNT}-\left(\mathrm{CrN}_{2}\right)^{\mathrm{a}}$

$177.7(3)$

$173.8(3)$

$\mathrm{N}-\mathrm{Cr}-\mathrm{N}$

$91.2(1)$

$90.37(5)$

${ }^{\mathrm{a}}$ Angle between the CNT-Cr vector and the $\mathrm{CrN}_{2}$ plane

\section{(b) VAc polymerizations under OMRP: V-70 initiator}

Before presenting the new results, it is necessary to review those already described in a recent communication. ${ }^{16}$ Compound $\mathbf{1}$ was shown to trap radicals produced by $\mathrm{V}-70$ in the presence of VAc, since a polymerization test with 
$\mathrm{VAc} / \mathrm{V}-70 / \mathbf{1}=500: 0.8: 1$ at $50^{\circ} \mathrm{C}$ for $4 \mathrm{~h}$, and then at $90^{\circ} \mathrm{C}$ gave only an $11 \%$ monomer conversion after $8 \mathrm{~h}\left(\mathrm{M}_{\mathrm{n}, \mathrm{SEC}}=11500 v \mathrm{~s}\right.$. the expected value of $\left.4730, \mathrm{M}_{\mathrm{w}} / \mathrm{M}_{\mathrm{n}}=1.81\right)$, which no longer increased upon warming at $90^{\circ} \mathrm{C}$ for $66 \mathrm{~h}$. Conversely, compound 5 gave a much higher monomer conversion, since a polymerization with VAc/V-70/5 = 500:0.8:1 gave a linearly growing $\mathrm{M}_{\mathrm{n}}$ up to a conversion of $70 \%\left(\mathrm{M}_{\mathrm{n}, \mathrm{SEC}}=67300 \mathrm{vs}\right.$. the expected value of $\left.30100, M_{w} / M_{n}=1.80\right)$ in $46 \mathrm{~h}$ under much milder conditions $(T$ $=30^{\circ} \mathrm{C}$ ). Although the controlling ability was poor (low initiator efficiency, high polydispersity), the sustained polymerization and the $M_{n}$ growth with conversion demonstrated the reversibility of radical trapping. The hypothesis that both complexes operate with formation of an organometallic dormant chain, $\mathrm{Cp}\left(\right.$ nacnac $\left.^{\mathrm{Ar}, \mathrm{Ar}}\right) \mathrm{Cr}^{\mathrm{III}}$-PVAc, with a much weaker $\mathrm{Cr}^{\mathrm{III}}$-PVAc bond when $\mathrm{Ar}=\operatorname{dipp}$ (compound 5) relative to $\mathrm{Ar}=\mathrm{xyl}($ compound $\mathbf{1})$ seemed fully consistent with DFT calculations of the bond strengths. The larger system with $\mathrm{Ar}=\operatorname{dipp}$ was not calculated, but a comparison of the bond dissociation energy for the two related systems with $\mathrm{Ar}=\mathrm{xyl}$ and $\mathrm{Ph}\left(19.7\right.$ and $28.4 \mathrm{kcal} \mathrm{mol}^{-1}$ at the B3LYP/6-31G* level, respectively) indicated a strong effect of the steric congestion created by the aryl substituents on the ability of the organometallic dormant chain to release free radicals in solution.

We now report subsequent studies with compounds $\mathbf{1}$ and $\mathbf{5}$, as well as with compounds 2-4, which revealed a more complex and interesting state of affairs. Compounds 2-4 were synthesized with the idea of fine controlling the $\mathrm{Cr}^{\mathrm{III}}$-PVAc BDE, thus allowing the development of a system capable of yielding a suitable 
polymerization rate and degree of control. However, a steric bulk increase on going from $\mathbf{1}$ to $\mathbf{2}$ and then to $\mathbf{3}$ and $\mathbf{4}$ did not produce any significant labilization of the

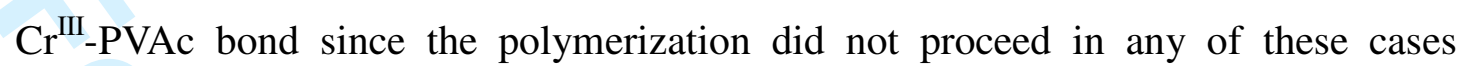
beyond $12 \%$ conversion for experiments carried out at $90^{\circ} \mathrm{C}$, see Figure 2. Indeed, the polymerization essentially stops in each case after an initial burst of monomer consumption, within the first 5-10 hours.

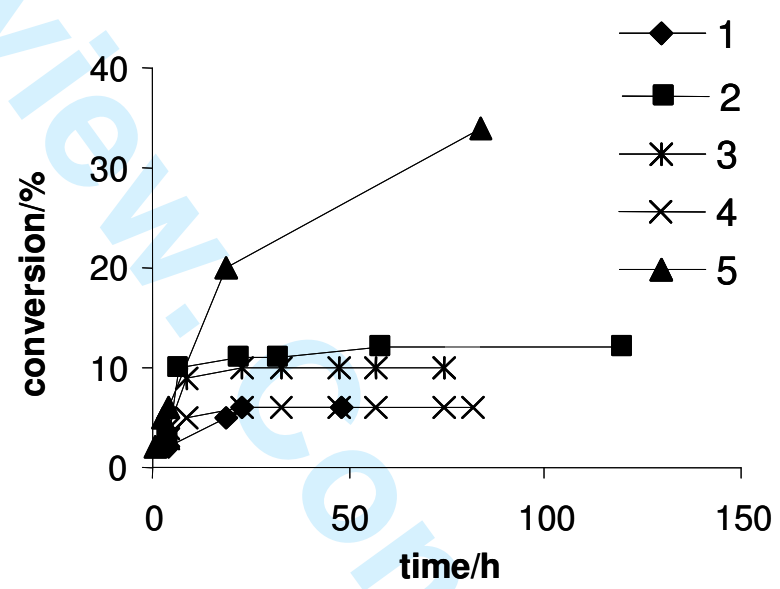

Figure 2. Conversion as a function of time for the VAc polymerization initiated by $\mathrm{V}-70$ in the presence of compounds $\mathbf{1 - 5}$. Conditions: $\mathrm{VAc} / \mathrm{V}-70 / \mathrm{Cr}^{\mathrm{II}}=$ 500:0.8:1. $\mathrm{T}=50^{\circ} \mathrm{C}$ for $4 \mathrm{~h}$, then $90^{\circ} \mathrm{C}$.

On the other hand, new polymerization experiments with compound 5, run at higher temperatures, gave a lower apparent polymerization rate constant., only $34 \%$ conversion after $84 \mathrm{~h}$ at $90^{\circ} \mathrm{C}$. The $\mathrm{M}_{\mathrm{n}}$ value increased linearly with conversion and the $\mathrm{M}_{\mathrm{w}} / \mathrm{M}_{\mathrm{n}}$ decreased to reach a value of only 1.21 for the final sample (see Figure 3), although the $M_{n}$ was much greater than expected (54 800 vs. 14 600). A polymerization process that takes place rapidly under mild conditions $\left(30^{\circ} \mathrm{C}\right)^{16}$ cannot become slower at a higher temperature while maintaining the same mechanism. It is 
more logical to think of a deactivation process (vide infra).

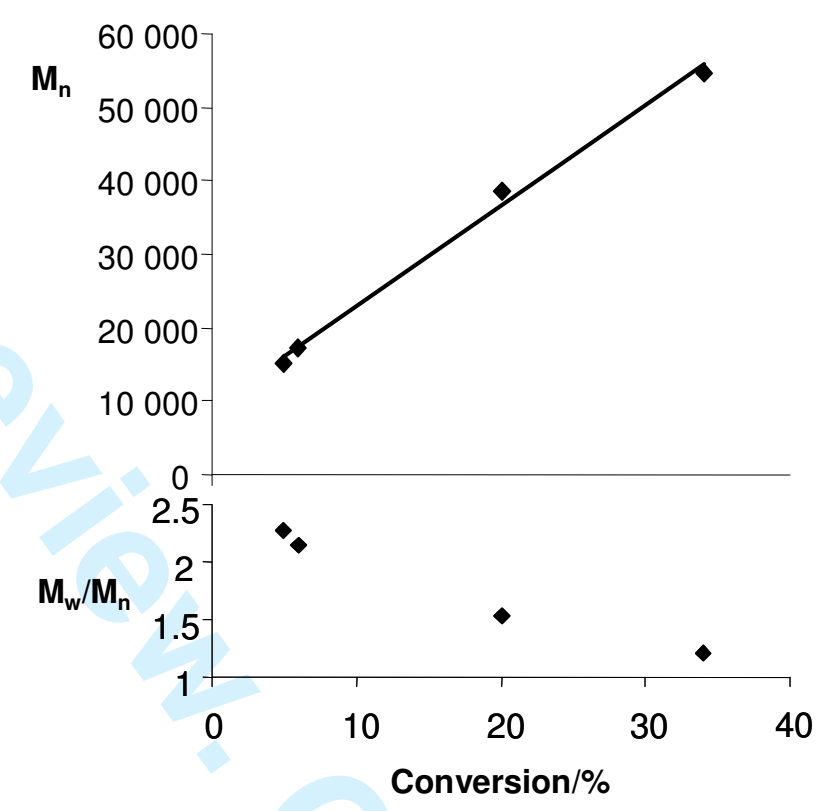

Figure 3. Number average molecular weight and polydispersity index for the PVAc obtained in the presence of compound 5. Conditions are as in Figure 2.

\section{(c) Design of a single-component chromium reagent as OMRP initiator.}

Well-defined $\mathrm{Cr}^{\mathrm{III}}-\mathrm{R}$ complexes could serve as single-component OMRP reagents if they possessed a $\mathrm{Cr}$-alkyl bond that was sufficiently weakened by steric interactions to readily undergo homolysis. ${ }^{12,13}$ To date, the success of synthetic routes to $\mathrm{CpCr}$ (nacnac)X complexes has depended on the degree of steric bulk in the target molecule. For the 2,6-i $\operatorname{Pr}_{2}$ substituted system, $\mathrm{CpCr}\left(\right.$ nacnac $\left.^{\text {dipp,dipp }}\right) \mathrm{Cl}$ was difficult to prepare by salt metathesis, and did not react cleanly with Grignard reagents. ${ }^{14}$ In contrast, reducing the size of the ortho substituents in the nacnac ligands was found to greatly improve both the synthesis and salt metathesis reactivity. ${ }^{15,43}$ For example, $\mathrm{CpCr}\left(\right.$ nacnac $\left.^{\mathrm{xyl}, \mathrm{xyl}}\right) \mathrm{Me}$ was readily prepared from $\mathrm{CpCr}\left(\right.$ nacnac $\left.^{\mathrm{xyl}, \mathrm{xyl}}\right) \mathrm{Cl}$ with $\mathrm{MeMgI}{ }^{15}$ 
Synthesis of the corresponding $\mathrm{CpCr}\left(\right.$ nacnac $\left.^{\text {dipp,dipp }}\right) \mathrm{Me}$ had necessitated the use of the corresponding $\mathrm{Cr}^{\mathrm{III}}$ triflate complex. ${ }^{14}$

Isolated $\mathrm{CpCr}\left(\right.$ nacnac $\left.^{\mathrm{xyl}, \mathrm{xyl}}\right) \mathrm{Me}$ does not serve as an effective single-component OMRP reagent. When $16.1 \mathrm{mg}$ of this $\mathrm{Cr}^{\mathrm{III}}$ methyl complex was dissolved in $4 \mathrm{~mL}$ of neat vinyl acetate, only a $9 \%$ mass conversion was observed after 48 hours at room temperature. The resulting polymer had both a high $\mathrm{M}_{\mathrm{n}}$ (83900 compared to 9140 expected $M_{n}$ ) and a high PDI of 3.4. The lack of steric pressure on the small methyl ligand and the relative instability of the $\mathrm{CH}_{3}$. radical should make the $\mathrm{Cr}^{\mathrm{III}}-\mathrm{CH}_{3} \mathrm{BDE}$ high and the homolytic dissociation unfavorable. Initiation to form $\mathrm{CH}_{3}$. and the $\mathrm{Cr}^{\mathrm{II}}$ radical trap will thus be inefficient at room temperature. However, the observation of a small amount of uncontrolled polymerization leading to high $\mathrm{M}_{\mathrm{n}}$ is consistent with the slow release of $\mathrm{CH}_{3}$. radicals which then react rapidly in neat vinyl acetate. ${ }^{44}$

For an efficient single component OMRP reagent, a $\mathrm{Cr}^{\mathrm{III}}$ alkyl complex is required that has a low $\mathrm{Cr}-\mathrm{R} \mathrm{BDE}$ and that generates a $\mathrm{R}$ - radical capable of reacting rapidly with vinyl acetate. The steric pressure exerted by the neopentyl ligand has often been used to encourage not only intramolecular deprotonation reactions, ${ }^{17-20}$ but also metal-alkyl bond homolysis. ${ }^{21-23}$ While several classes of even-electron monomeric chromium neopentyl complexes are known for $\mathrm{Cr}^{\mathrm{II}}, 31,45 \mathrm{Cr}^{\mathrm{IV}}, 46,47$ and $\mathrm{Cr}^{\mathrm{VI}}{ }^{48-50}$ well-defined $\mathrm{Cr}^{\mathrm{III}}$ neopentyl complexes are relatively unexplored. ${ }^{51}$

The synthesis of compound $\mathrm{CpCr}\left(\operatorname{nacnac}^{\mathrm{xyl}, \mathrm{xyl}}\right) \mathrm{Cl}(\mathbf{6})$ was achieved by reacting $\mathrm{CrCl}_{3}$ with one equivalent of $\mathrm{Li}\left(\operatorname{nacnac}^{\mathrm{xyl}, \mathrm{xyl}}\right)$, followed by one equivalent of $\mathrm{NaCp}$ to yield an air stable crystalline solid. The geometry of $\mathbf{6}$ (Figure 4) can be described as a 
"three-legged piano stool" and is ubiquitous of half-sandwich $\mathrm{Cr}^{\mathrm{III}}$ complexes. The $\mathrm{Cr}-\mathrm{Cl}$ bond length of 2.3082(5) $\AA$ is similar to that found in $\mathrm{CpCr}\left(\right.$ nacnac $\left.^{\text {dipp,dipp }}\right) \mathrm{Cl},{ }^{14}$ as well as other cylcopentadienyl $\mathrm{Cr}^{\mathrm{III}}$ complexes with terminal $\mathrm{Cl}$ groups, like $\mathrm{CpCr}(\mathrm{acac}) \mathrm{Cl}$ and $\mathrm{Cp} * \mathrm{Cr}(\mathrm{acac}) \mathrm{Cl}\left(\mathrm{Cr}-\mathrm{Cl}\right.$ of $2.299(1)$ and $2.307(1) \AA$, respectively) ${ }^{52}$ It is also similar to the $\mathrm{Cr}-\mathrm{Cl}$ distance in 6-coordinate $\mathrm{Cr}^{\mathrm{III}}$ nacnac complexes with terminal $\mathrm{Cl}$ ligands $\left(2.346(1) \AA\right.$ for $\mathrm{Cr}\left(\operatorname{nacnac}^{\mathrm{Ph}, \mathrm{Ph}}\right) \mathrm{Cl}_{2}(\mathrm{THF})_{2}{ }^{53}$ and $2.2947(12) \AA$ for $\mathrm{Cr}\left(\right.$ nacnac $\left.\left.^{\text {dipp,dipp }}\right)\left(\mathrm{O}_{2} \mathrm{CMe}\right) \mathrm{Cl}(\mathrm{THF})^{54}\right)$, while 5-coordinate $\mathrm{Cr}^{\mathrm{III}}$ nacnac complexes display shorter $\mathrm{Cr}-\mathrm{Cl}$ bond lengths (2.233(2) $\AA$ and 2.2294(14) for the terminal chloride ligands in $\left[\mathrm{Cr}\left(\text { nacnac }^{\text {dipp,dipp }}\right) \mathrm{Cl}(\mu-\mathrm{Cl})\right]_{2}$ and $\mathrm{Cr}\left(\right.$ nacnac $\left.^{\text {dipp,dipp }}\right)\left[(\mathrm{OCPh})_{2} \mathrm{CH}\right] \mathrm{Cl}$, respectively). ${ }^{54}$ Unlike the geometries of $\mathbf{2}$ and $\mathbf{3}$, the $\mathrm{Cr}$ atom deviates significantly from the plane of the nacnac ligand, toward the $\mathrm{Cl}$ atom. The $\mathrm{Cr}$ in 6 lies 0.615(3) $\AA$ out of the imaginary plane defined by the N1-C2-C4-N2 atoms, which is smaller than the $0.72 \AA$ out-of-plane distortion previously observed for the bulkier $\mathrm{CpCr}\left(\right.$ nacnac $\left.{ }^{\text {dipp,dipp }}\right) \mathrm{Cl}^{14}$ Relative to the $\mathrm{Cr}^{\mathrm{II}}$ structures, the $\mathrm{Cr}-\mathrm{CNT}$ distance is slightly shorter, whereas the $\mathrm{Cr}-\mathrm{N}$ distances are not significantly different.

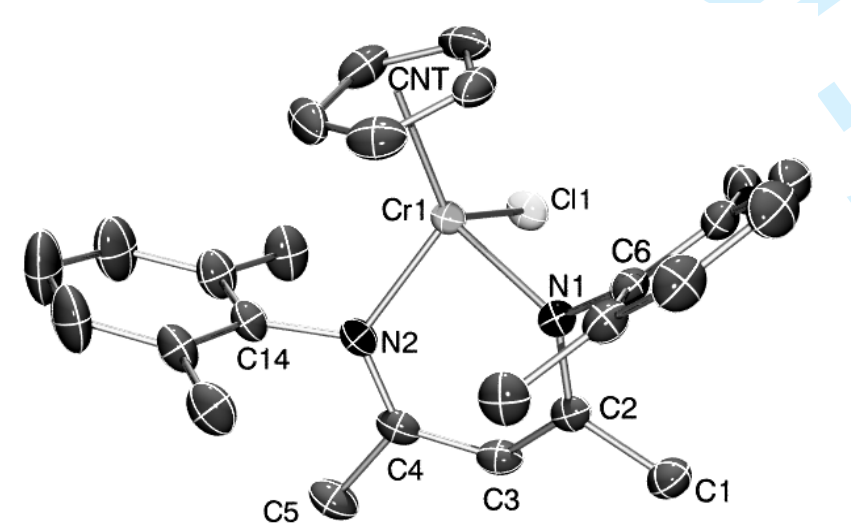

Figure 4. Thermal ellipsoid diagram (50\%) of compound 6. All H atoms are omitted and only one Cp orientation is shown for clarity. Selected bond lengths $(\AA)$ : 
$\mathrm{Cr}(1)-\mathrm{N}(1), 2.018(2) ; \mathrm{Cr}(1)-\mathrm{N}(2), 2.020(2) ; \mathrm{Cr}(1)-\mathrm{CNT}, 1.92(2) ; \mathrm{Cr}(1)-\mathrm{Cl}(1)$, 2.3082(5). Selected bond angles (deg): $\mathrm{N}(1)-\mathrm{Cr}(1)-\mathrm{N}(2), 90.47(7) ; \mathrm{N}(1)-\mathrm{Cr}(1)-\mathrm{Cl}(1)$, 94.28(5); N(2)-Cr(1)-Cl(1), 93.14(5); CNT-Cr(1)-N(1), 124.8(4); CNT-Cr(1)-N(2), 125.0(4); CNT-Cr(1)-Cl(1), 120.34(6); CNT- $\left(\mathrm{CrN}_{2}\right)^{\mathrm{a}}, 160.5(4) .{ }^{\mathrm{a}}$ Angle between the $\mathrm{CNT}-\mathrm{Cr}$ vector and the $\mathrm{CrN}_{2}$ plane.

While 6 is a useful precursor to $\mathrm{CpCr}\left(\operatorname{nacnac}^{\mathrm{xyl}, \mathrm{xyl}}\right) \mathrm{Me},{ }^{15}$ attempts to install more sterically demanding alkyl ligands once again required the use of a better leaving group. The reaction of compound $\mathbf{6}$ with one equivalent of AgOTs provides compound 7 in high yields as an air stable crystalline solid (Figure 5). Preliminary reactions between 6 and AgOTf or AgOTs had indicated that the $\mathrm{Cr}^{\mathrm{III}}$ tosylate was less air sensitive and more crystalline than the $\mathrm{Cr}^{\mathrm{III}}$ triflate complex. The $\mathrm{Cr}-\mathrm{O}$ bond length in $7,1.9839(15) \AA$, is slightly shorter than the $2.030(1)$ observed for the $\mathrm{CpCr}\left(\right.$ nacnac $\left.^{\text {dipp,dipp }}\right)(\mathrm{OTf}),{ }^{14}$ which may be attributable to the lower electron withdrawing power of the para-tolyl substituent compared to $\mathrm{CF}_{3}$, the decreased steric demand of the 2,6- $\mathrm{Me}_{2} \mathrm{C}_{6} \mathrm{H}_{3}$ substituted nacnac, or both.

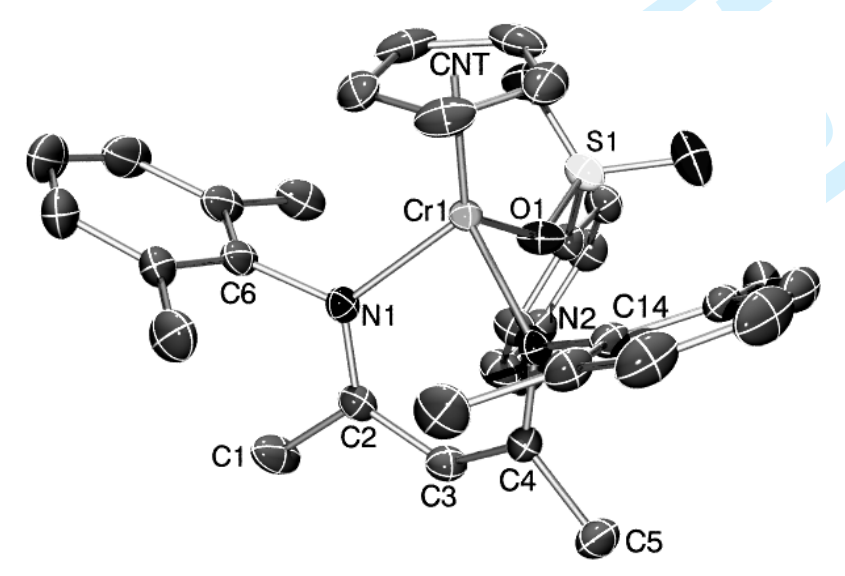

Figure 5. Thermal ellipsoid diagram (50\%) of compound 7. All $\mathrm{H}$ atoms are omitted for clarity. Selected bond lengths $(\AA)$ : $\mathrm{Cr}(1)-\mathrm{N}(1), 2.0038(16) ; \mathrm{Cr}(1)-\mathrm{N}(2)$, 2.0019(17); Cr(1)-CNT, 1.896; Cr(1)-O(1), 1.9839(15). Selected bond angles (deg): $\mathrm{N}(1)-\mathrm{Cr}(1)-\mathrm{N}(2), 90.17(7) ; \mathrm{N}(1)-\mathrm{Cr}(1)-\mathrm{O}(1), 91.45(7) ; \mathrm{N}(2)-\mathrm{Cr}(1)-\mathrm{O}(1), 92.48(7)$; 
CNT-Cr(1)-N(1)，125.74； CNT-Cr(1)-N(2)，123.82； CNT-Cr(1)-O(1)，123.32; $\mathrm{Cr}(1)-\mathrm{O}(1)-\mathrm{S}(1), 135.77(9)$.

The reaction of compound 7 with one-half equivalent of $\operatorname{Mg}\left(\mathrm{CH}_{2} \mathrm{CMe}_{3}\right)_{2} \cdot 1.05(1,4$-dioxane $)$ gave $\mathrm{CpCr}\left(\right.$ nacnac $\left.^{\mathrm{xyl}, \mathrm{xyl}}\right) \mathrm{Np} \quad(\mathbf{8})$, where $\mathrm{Np}=$ neopentyl, $\mathrm{CH}_{2} \mathrm{CMe}_{3}$. The use of the halide-free dialkyl $\mathrm{Mg}$ reagent was required to avoid unwanted substitution of the tosylate ligand in $\mathbf{7}$ with a halide prior to alkylation to form $\mathbf{8}$. Complex $\mathbf{8}$ was found to be highly soluble in non-polar solvents, similar to the previously reported $\mathrm{CpCr}\left(\right.$ nacnac $\left.^{\mathrm{xyl}, \mathrm{xyl}}\right) \mathrm{Me} \cdot{ }^{14,15}$ The structural characterization of $\mathbf{8}$ has been achieved by single crystal X-ray diffraction (Figure 6). The $\mathrm{Cr}-\mathrm{C}(27)$ bond is significantly elongated in $8(2.136(3) \AA)$ compared to the $2.076(2) \AA$ observed previously for the corresponding $\mathrm{Cr}^{\mathrm{III}}$ methyl complex. ${ }^{15,43} \mathrm{The} \mathrm{Cr}-\mathrm{N}$ bond lengths in $\mathbf{8}$ are also slightly longer, and the $\mathrm{Cr}-\mathrm{C}(27)-\mathrm{C}(28)$ angle is $135.1(2)^{\mathbf{o}}$, indicative of the strain imposed by the ${ }^{\mathrm{t}} \mathrm{Bu}$ substituent of the neopentyl ligand. Solutions of $\mathbf{8}$ are purple, exhibiting strong bands in the UV-visible spectrum at $404 \mathrm{~nm}$ and $567 \mathrm{~nm}$. The strong absorbance around $550 \mathrm{~nm}$ seems characteristic of $\mathrm{CpCr}$ (nacnac)(alkyl) complexes: the increase in absorbance at $530 \mathrm{~nm}$ due to formation of $\mathrm{CpCr}($ nacnac)Me was used to monitor the kinetics of iodomethane activation with CpCr(nacnac) complexes 1-3. ${ }^{15}$ Although 8 was stable in solution to allow for recrystallization from hexanes, decomposition took place upon dilution (necessary for UV/Vis characterization) to yield $\mathrm{CpCr}\left(\operatorname{nacnac}^{\mathrm{xyl}, \mathrm{xyl}}\right), \mathbf{1}$. The decrease in stability of $\mathbf{8}$ at high dilution is consistent with the facile homolytic $\mathrm{Cr}-\mathrm{C}$ bond cleavage, paralleling the reactivity of other neopentyl complexes, ${ }^{21-23}$ with formation of 
compound $\mathbf{1}$ and an extremely reactive neopentyl radical, and indicated the potential for complex $\mathbf{8}$ to be used as a single component reagent to initiate and control the radical polymerization of vinyl acetate.

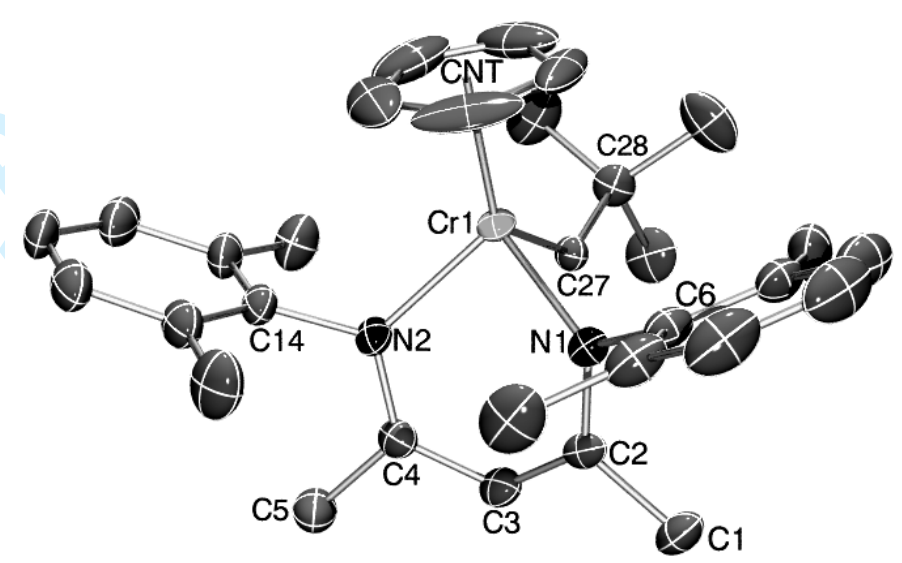

Figure 6. Thermal ellipsoid diagram (50\%) of compound 8. Compound 8 has two independent molecules in the crystal lattice, only one is shown and all $\mathrm{H}$ atoms are omitted for clarity. Selected bond lengths $(\AA)$ : $\mathrm{Cr}(1)-\mathrm{N}(1), 2.046(2) ; \mathrm{Cr}(1)-\mathrm{N}(2)$, 2.051(2); $\mathrm{Cr}(1)-\mathrm{CNT}, 1.949 ; \mathrm{Cr}(1)-\mathrm{C}(27), 2.136(3)$. Selected bond angles (deg): $\mathrm{N}(1)-\mathrm{Cr}(1)-\mathrm{N}(2), \quad 89.71(9) ; \quad \mathrm{N}(1)-\mathrm{Cr}(1)-\mathrm{C}(27), \quad 93.50(10) ; \quad \mathrm{N}(2)-\mathrm{Cr}(1)-\mathrm{C}(27)$, 93.63(10); CNT-Cr(1)-N(1), 123.03; CNT-Cr(1)-N(2), 122.29; CNT-Cr(1)-C(27), 125.39; $\mathrm{Cr}(1)-\mathrm{C}(27)-\mathrm{C}(28), 135.1(2)$.

\section{(d) OMRP of VAc with complex 8}

Polymerizations of VAc in the presence of complex $8(\mathrm{VAc} / \mathbf{8}=1200: 1)$ at room temperature gave a linearly growing $\mathrm{M}_{n}$ up to a monomer conversion of $14 \%$ after $400 \mathrm{~h}\left(\mathrm{M}_{\mathrm{n}, \mathrm{SEC}}=16200 v \mathrm{~s}\right.$. the expected value of $\left.15100, \mathrm{M}_{\mathrm{w}} / \mathrm{M}_{\mathrm{n}}=1.46\right)$, see Figure 7. These results contrasts with the uncontrolled polymerization observed with $\mathrm{CpCr}\left(\right.$ nacnac $\left.^{\mathrm{xyl}, \mathrm{xyl}}\right) \mathrm{Me}$ under the same conditions, as discussed above. There is no visible induction period and the good agreement between the observed and calculated $M_{n}$ demonstrates the increased initiator efficiency compared with the OMRP reactions 
with the V-70 initiator. However, the progressive decrease of the polymerization rate constant (decreasing slope in Figure 7a) suggests that partial deactivation of the growing chains occurs, which also causes the broad molecular weight distribution.

(a)

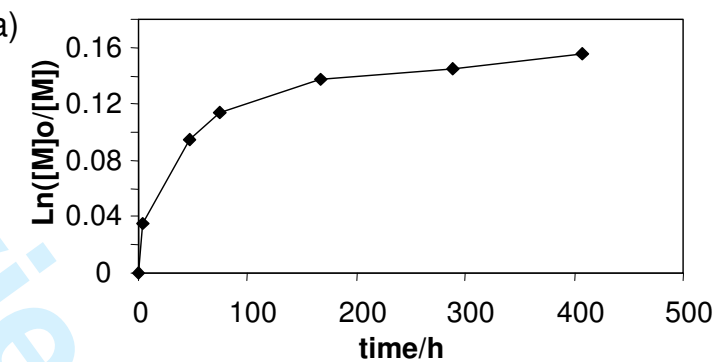

(b)

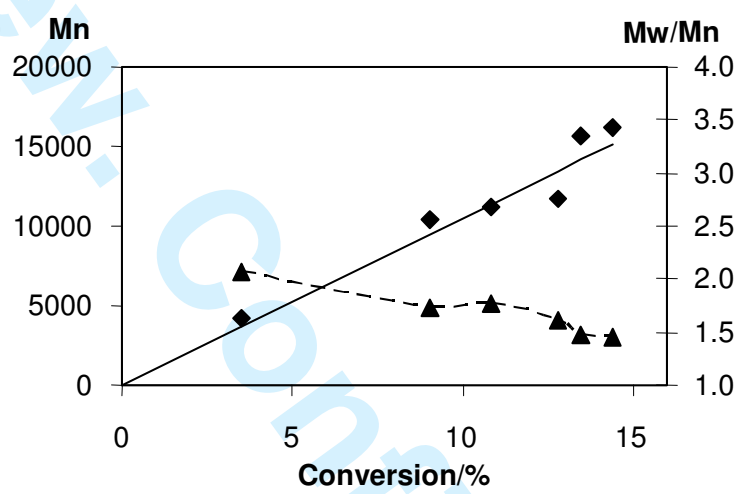

Figure 7. (a) $\ln \left([\mathrm{VAc}]_{0} /[\mathrm{VAc}]\right)$ as a function of time for the VAc polymerization initiated by compound $\mathbf{8}$. Conditions: VAc/8 $=1200: 1$. $T=$ room temp. (b) Variation of the $\mathrm{M}_{\mathrm{n}, \mathrm{SEC}}$ (diamonds) and $\mathrm{M}_{\mathrm{w}} / \mathrm{M}_{\mathrm{n}}$ (triangles) as a function of conversion; the solid line represents $M_{n, t h}$.

Spectroscopic analysis of the polymerization reaction of vinyl acetate with $\mathbf{8}$ revealed absorbance peaks at $422 \mathrm{~nm}$ and $556 \mathrm{~nm}$, at a reaction time of $10 \mathrm{~min}$, indicating that $\mathbf{8}$ had been completely consumed, presumably being transformed into the $\mathrm{CpCr}\left(\right.$ nacnac $\left.^{\mathrm{xyl}, \mathrm{xyl}}\right)(\mathrm{PVAc})$ dormant species. This is again in contrast to the previously discussed reaction of $\mathrm{CpCr}\left(\operatorname{nacnac}^{\mathrm{xyl}, \mathrm{xyl}}\right) \mathrm{Me}$ in vinyl acetate, where after 48 hours the absorbance peak of the $\mathrm{Cr}^{\mathrm{III}}$ methyl starting material was still evident at 546 nm. Throughout the progress of the polymerization reaction initiated by $\mathbf{8}$, the 
UV/Vis spectrum further evolved to yield a shift of the major band toward higher frequency $(412 \mathrm{~nm})$, while the $556 \mathrm{~nm}$ band decreased in intensity, see Figure 8. This spectral evolution parallels the observed decrease in polymerization rate (Figure 7). After $400 \mathrm{~h}$ of polymerization process, the sample was heated at $70^{\circ} \mathrm{C}$ for $3.5 \mathrm{~h}$ to produce a colour change from purple to green (incident light) and orange (transmitted light) with the higher energy absorption band increasing in intensity and the $556 \mathrm{~nm}$ band disappearing and being replaced by a less intense band at $575 \mathrm{~nm}$. The results suggested that, even though the rate of polymerization had slowed down significantly (see Figure 7), there was still some $\mathrm{CpCr}^{\mathrm{III}}\left(\right.$ nacnac $\left.^{\mathrm{xyl}, \mathrm{xyl}}\right)(\mathrm{PVAc})$ compound present after $400 \mathrm{~h}$ of polymerization, which underwent further reactivity once heated.

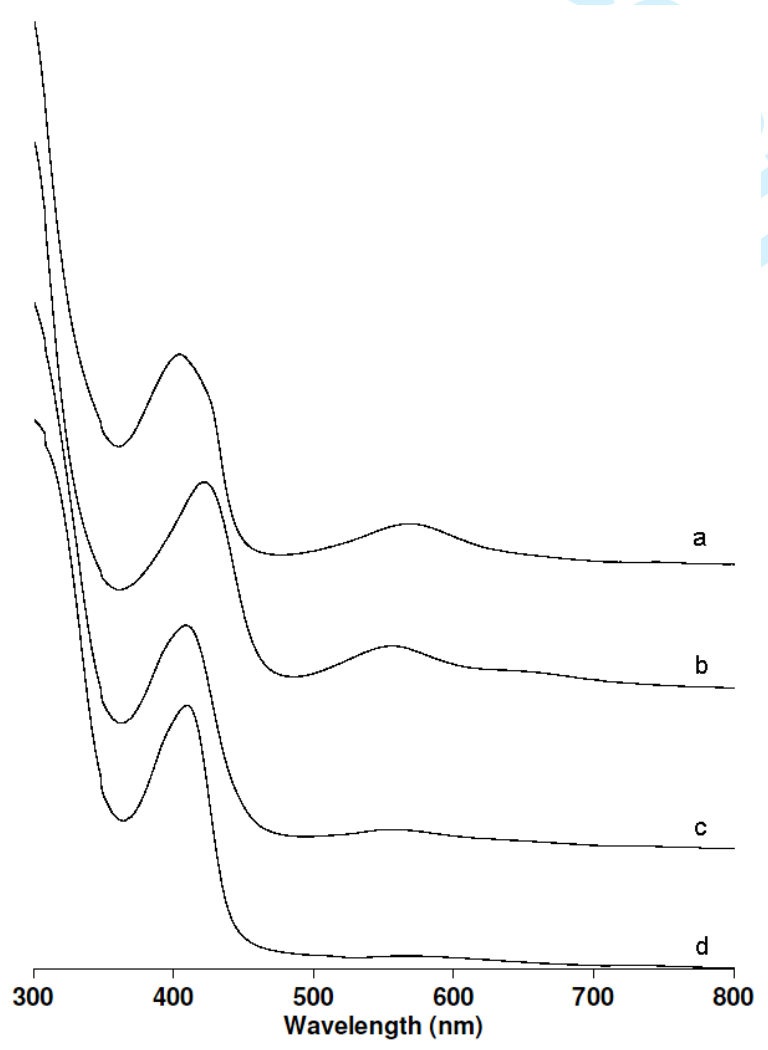

Figure 8. Evolution of the UV/Vis properties during the VAc polymerization controlled by compound $\mathbf{8}$ (conditions as shown in Figure 7). (a) Initial spectrum of compound 8; (b) after 10 min of polymerization; (c) after $400 \mathrm{~h}$ of polymerization; (d) after warming to $70^{\circ} \mathrm{C}$ (spectrum of the decomposition product). 
It is striking to compare the behaviour of the polymerization initiated by compound $\mathbf{8}$ on one side (14\% in $400 \mathrm{~h}$ at room temperature, Figure 7 ) with that initiated by the $1 / \mathrm{V}-70$ mixture $\left(5 \%\right.$ in $50 \mathrm{~h}$ at $90^{\circ} \mathrm{C}$, Figure 2$)$, both leading in principle to the same OMRP equilibrium. This clearly proves that the $\mathrm{CpCr}^{\mathrm{III}}\left(\right.$ nacnac $\left.^{\mathrm{xyl}, \mathrm{xyl}}\right)(\mathrm{PVAc})$ dormant chain can be reversibly reactivated under mild conditions to sustain the OMRP of vinyl acetate, but it also suffers irreversible thermal deactivation, even at room temperature at a slow rate, and much faster at more elevated temperatures.

It is interesting to compare the relatively slow polymer growth in the presence of the $\mathrm{CpCr}\left(\right.$ nacnac $\left.^{\mathrm{xyl}, \mathrm{xyl}}\right)$ system and the previously reported ${ }^{16}$ faster polymer growth in the presence of the $\mathrm{CpCr}\left(\right.$ nacnac $\left.^{\text {dipp,dipp }}\right)$ system $\left(70 \%\right.$ conversion in $46 \mathrm{~h}$ at $\left.30^{\circ} \mathrm{C}\right)$. This difference confirms the previously proposed steric effect on the homolytic bond dissociation energy, which is further investigated at the theoretical level in the next section.

\section{(e) DFT study of the OMRP trapping processes}

The previous communication reported geometry optimizations at the full QM level using density functional theory (DFT) for $\mathrm{CpCr}^{\mathrm{II}}\left(\mathrm{nacnac}^{\mathrm{Ar}, \mathrm{Ar}}\right)$ and $\mathrm{CpCr}^{\mathrm{III}}\left(\right.$ nacnac $\left.^{\mathrm{Ar}, \mathrm{Ar}}\right)(\mathrm{CHMeOOCMe})$ (a model of the OMRP dormant chain), leading to the calculation of the $\mathrm{Cr}^{\mathrm{III}}-\mathrm{C}$ BDE values of 28.4 and $19.7 \mathrm{kcal} / \mathrm{mol}$ for $\mathrm{Ar}=\mathrm{Ph}$ and Xyl, respectively. ${ }^{16}$ This shows a tremendous steric effect of the nacnac aryl 
substituents on the $\mathrm{Cr}^{\mathrm{III}}-\mathrm{C}$ bond fragility, which is also reflected in the optimized $\mathrm{Cr}^{\mathrm{III}}-\mathrm{C}$ distances $(2.109$ and $2.124 \AA$, respectively). Calculations of the $\mathrm{Ar}=\operatorname{dipp}$ system were not carried out because too time consuming at the full QM level. We now report QM/MM results for the same systems as well as for the bulkier dipp system in terms of both energetics and radical trapping barriers. The energetic results and views of the optimized structures are shown in Figure 9, whereas the essential bonding parameters are given in Table 2. All optimized geometries are available in the Supporting Information in the form of Cartesian coordinates. The calculations were carried out with imposition of the experimentally determined spin state $(S=3 / 2$ for the alkylchromium(III) complexes and $\mathrm{S}=2$ for the chromium(II) trapping species), leading to calculated structure in excellent agreement with those determined crystallographically for complexes $\mathbf{1}$ and $\mathbf{5}$. The calculated $\mathrm{Cr}-\mathrm{C}$ bond lengths for the cylclopentadienyl ligand are longer than those observed experimentally: ${ }^{55}$ the CNT-Cr distances for the $\mathrm{Cr}^{\mathrm{II}} \mathrm{Xyl}$ and Dipp nacnac complexes were 2.022 and 2.016 $\AA$ for $\mathbf{1}$ and $\mathbf{5}$, respectively.

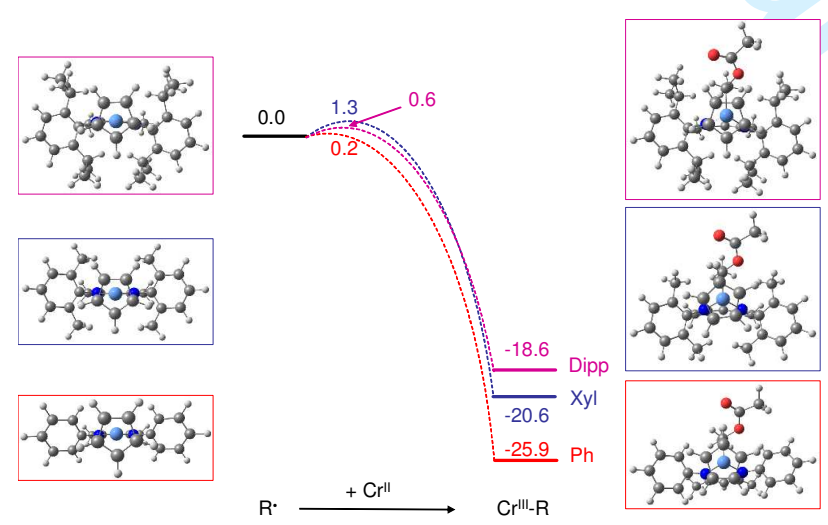

Figure 9. Optimized geometries and $\mathrm{QM} / \mathrm{MM}$ relative energies (in $\mathrm{kcal} / \mathrm{mol}$ ) of geometry-optimized $\mathrm{CpCr}^{\mathrm{II}}\left(\right.$ nacnac $\left.^{\mathrm{Ar}, \mathrm{Ar}}\right)$ and $\mathrm{CpCr}^{\mathrm{III}}\left(\right.$ nacnac $\left.^{\mathrm{Ar}, \mathrm{Ar}}\right)(\mathrm{CHMeOOCMe})$ for 
$\mathrm{Ar}=\mathrm{Ph}, \mathrm{Xyl}$ and Dipp.

Table 2. Selected bond distances $(\AA)$ and angles $\left({ }^{\circ}\right)$ for the B3LYP//UFF optimized geometries.

The energetic results in terms of $\mathrm{DBE}\left(\mathrm{Cr}^{\mathrm{III}}-\mathrm{C}\right)$ for the $\mathrm{Ph}$ and $\mathrm{Xyl}$ systems are quite close to those previously obtained at the full QM level, although the steric labilization exerted by the four Me groups is predicted as less severe by the QM/MM calculations relative to the full QM level. The present calculation uses a polarized SDD basis set for the $\mathrm{Cr}$ atom, which is considered as more balanced than the LANL2DZ basis set without polarization functions previously used in the full QM calculations. ${ }^{16}$ The presence of a steric effect is confirmed on going from the Xyl to the Dipp substituents, where the four $i \mathrm{Pr}$ groups induce a further $\mathrm{Cr}^{\mathrm{III}}-\mathrm{C}$ bond labilization by $2.0 \mathrm{kcal} / \mathrm{mol}$ relative to four Me groups. This labilization is accompanied by a significant lengthening of the $\mathrm{Cr}^{\mathrm{III}}-\mathrm{C}$ bond, in the order $\mathrm{Ph}(2.091 \AA)$ 
$<$ Xyl $(2.115 \AA)<\operatorname{Dipp}(2.139 \AA)$.

We have also optimized the transition state leading from the $\mathrm{CpCr}^{\mathrm{II}}\left(\right.$ nacnac $^{\mathrm{Ar}, \mathrm{Ar}}$ ) complex plus free radical to the OMRP dormant species. The coordination geometry is quite close to that of the $\mathrm{Cr}^{\mathrm{II}}$ complex with a rather long $\mathrm{Cr}^{\mathrm{II}}-\mathrm{C}$ distance, i.e. the transition state is early for the radical trapping process, consistent with the very low calculated energy barrier. The barrier is lowest, as expected, for the less encumbered Ph derivative, whereas the most encumbered Dipp system yields a lower barrier than the Xyl system with intermediate steric demand. Although the barrier for trapping the radical is very low for all three systems, the unexpectedly lower barrier for the Dipp derivative may be attributable to the structure of the $\mathrm{Cr}^{\mathrm{II}}$ complex. The calculated ground state structure of $\mathrm{CpCr}\left(\right.$ nacnac $\left.^{\text {dipp,dipp }}\right)$ faithfully reproduces the slight bowing of the $\mathrm{N}$-aryl substituents out of the plane defined by the nacnac ligand that was observed in the X-ray structure of $1 .{ }^{14}$ As suggested by a helpful reviewer, this sterically-induced initial deformation of the $\mathrm{Cr}^{\mathrm{II}}$ Dipp complex may permit a slightly lower energy approach of the alkyl radical compared to $\operatorname{CpCr}\left(\operatorname{nacnac}^{\mathrm{xyl}, \mathrm{xyl}}\right)$ which does not display this distortion.

\section{(f) Isolation of the deactivated complex}

As discussed above, UV-vis analysis of the $\mathrm{Cr}^{\mathrm{III}}$ neopentyl compound in vinyl acetate suggested that while $\mathbf{8}$ was consumed within minutes at room temp, a subsequent thermal decomposition reaction occurred and that this is accelerated by heating. To determine the ultimate fate of the organochromium complex, the 
thermolyzed reaction mixture of $35.8 \mathrm{mg}$ of $\mathbf{8}$ in $4 \mathrm{~mL}$ of vinyl acetate was evacuated and the unknown $\mathrm{Cr}$ species was extracted from the PVAc with diethyl ether. After filtration, concentration, and storage at $-35^{\circ} \mathrm{C}$ for two weeks, $7.9 \mathrm{mg}$ of X-ray quality crystals of $\mathrm{CpCr}\left(\right.$ nacnac $\left.{ }^{\mathrm{xyl}, \mathrm{xyl}}\right) \mathrm{OC}(\mathrm{O}) \mathrm{Me}(\mathbf{9})$ (Figure 10) were obtained, corresponding to a $23 \%$ isolated yield based on $\mathbf{8}$.

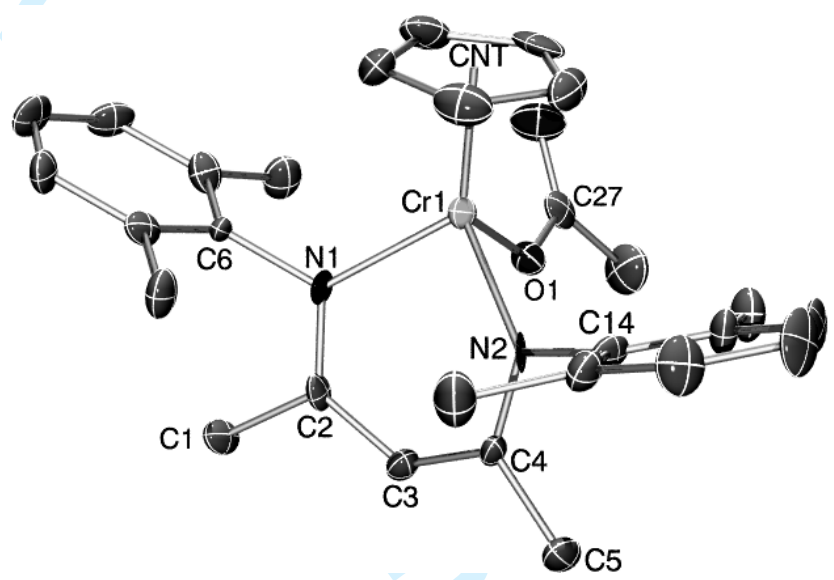

Figure 10. Thermal ellipsoid diagram (50\%) of 9 . All $\mathrm{H}$ atoms are omitted for clarity. Selected bond lengths $(\AA)$ : $\mathrm{Cr}(1)-\mathrm{N}(1), 2.010(5)$; $\mathrm{Cr}(1)-\mathrm{N}(2), 2.004(6)$; $\mathrm{Cr}(1)-\mathrm{CNT}$, 1.914; $\mathrm{Cr}(1)-\mathrm{O}(1), 1.952(5) ; \mathrm{C}(27)-\mathrm{O}(1), 1.278(9) ; \mathrm{C}(27)-\mathrm{O}(2), 1.230(9)$. Selected bond angles (deg): $\quad \mathrm{N}(1)-\mathrm{Cr}(1)-\mathrm{N}(2), \quad 90.7(2) ; \quad \mathrm{N}(1)-\mathrm{Cr}(1)-\mathrm{O}(1), \quad 92.7(2)$; $\mathrm{N}(2)-\mathrm{Cr}(1)-\mathrm{O}(1), \quad 88.6(2) ; \quad \mathrm{CNT}-\mathrm{Cr}(1)-\mathrm{N}(1), \quad 124.94 ; \quad \mathrm{CNT}-\mathrm{Cr}(1)-\mathrm{N}(2), 123.34 ;$ CNT-Cr(1)-O(1), 125.92; Cr(1)-O(1)-C(27), 133.6(5).

The independent synthesis of 9 was achieved by the reaction of 6 with one equivalent of $\mathrm{AgOAc}$, with $\mathrm{UV}$-visible spectroscopic analysis confirming that $\mathbf{9}$ was the thermal decomposition product of the polymerization reaction. Upon reexamination of the $\mathrm{V}-70$ initiated OMRP experiments, UV-vis spectroscopy confirmed that the $\mathrm{Cr}^{\mathrm{III}}$ acetate complex was a common termination pathway for all of the $\mathrm{Cr}$ mediated vinyl acetate polymerization reactions conducted at elevated 
temperatures. Suspicions arose about the possibility of $\mathrm{Cr}^{\mathrm{III}}$ acetate formation by oxidative addition of $\mathrm{a}=\mathrm{CH}-\mathrm{OC}(\mathrm{O}) \mathrm{CH}_{3}$ moiety from the polymer chain. However, a control experiment showed no signs of reactivity for compound $\mathbf{1}$ towards commercially obtained PVAc upon heating to $50^{\circ} \mathrm{C}$ for $24 \mathrm{~h}$. Similarly, prolonged heating of $\mathbf{1}$ in vinyl acetate does not result in any change in the UV/Vis spectrum of $\mathbf{1}$. These results suggested a more complicated mechanism for the formation of $\mathrm{CpCr}$ (nacnac)OAc. The proposed mechanism for the formation of $\mathbf{9}$ is that of $\beta$-acetate elimination arising from a 2,1-insertion (head-to-head) of the monomer, as shown in Scheme 3. Head-to-head insertion is known to be particularly problematic for the radical polymerization of vinyl acetate, due to the relatively poor regioselectivity of radical addition. ${ }^{1,5}$ Note that the 2,1-insertion step may lead to the generation of a dormant species with a presumably stronger $\mathrm{Cr}^{\mathrm{III}}-\mathrm{C}$ bond, which could also contribute for a gradual slow down of the polymerization process. 


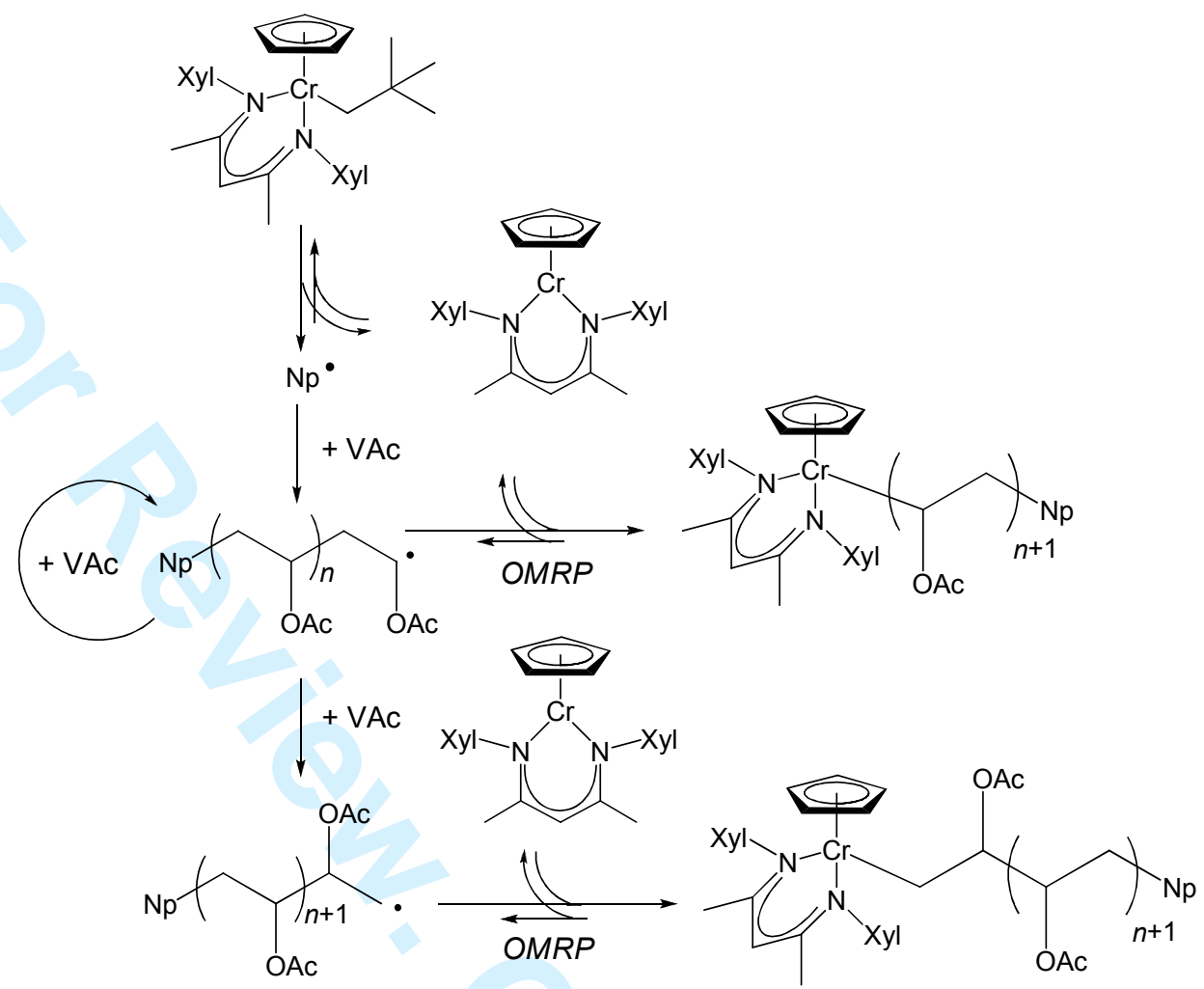

Scheme 3

Elimination of $\beta$-acetate groups has been well documented as a decomposition mode in attempts to copolymerize ethylene and vinyl acetate with $\mathrm{Ni}$ and $\mathrm{Pd}$ catalysts. ${ }^{2,3}$ We point out, however, that the $\beta$-acetate elimination process from the newly formed dormant species is not likely to follow a classical $\beta$-elimination mechanism, because this requires an open coordination site on $\mathrm{Cr}$ capable of accepting the two additional electrons furnished by the incoming acetate group. While the metal is electronically unsaturated (15 electrons) and metal-based orbitals are indeed available, the latter are however half-occupied because of the ubiquitous spin quartet configuration of half-sandwich $\mathrm{Cr}^{\mathrm{III}}$. Expansion to a 17-electron configuration would require an energetically costly (for $\mathrm{Cr}^{\mathrm{III}}$ ) electron pairing process. ${ }^{56-58}$ A likely 
alternative is acetate group transfer from the $\beta-\mathrm{C}$ atom of the radical chain to the $\mathrm{Cr}$ center, as shown in Scheme 4. Unfortunately, we were unable to observe vinyl chain end resonances in the ${ }^{13} \mathrm{C}$ NMR spectrum of the polymer isolated from thermolysis of 8 in vinyl acetate to provide additional support for the mechanism proposed in Scheme 4. Homolytic bond rupture followed by atom (or group) transfer has been observed for R-Co(porphyrin) complexes where the coordination geometry has no cis vacant site available to accommodate the migrating atom or group. ${ }^{59}$ It is quite possible that, following a 2,1-insertion, the resulting $\mathrm{CH}_{2}$-terminated radical undergoes competitive $\beta$-acetate transfer as shown in Scheme 4 or $\mathrm{Cr}^{\mathrm{III}}-\mathrm{C}$ bond formation as shown in Scheme 3, thus yielding a mixture of acetate complex and a less active $\mathrm{Cp}\left(\right.$ nacnac $\left.^{\mathrm{xyl}, \mathrm{xyl}}\right) \mathrm{Cr}-\mathrm{CH}_{2} \mathrm{CH}(\mathrm{OAc})-\mathrm{PVAc}$ dormant species. Only upon warming the latter can be reactivated and eventually be completely transformed into the final acetate product.
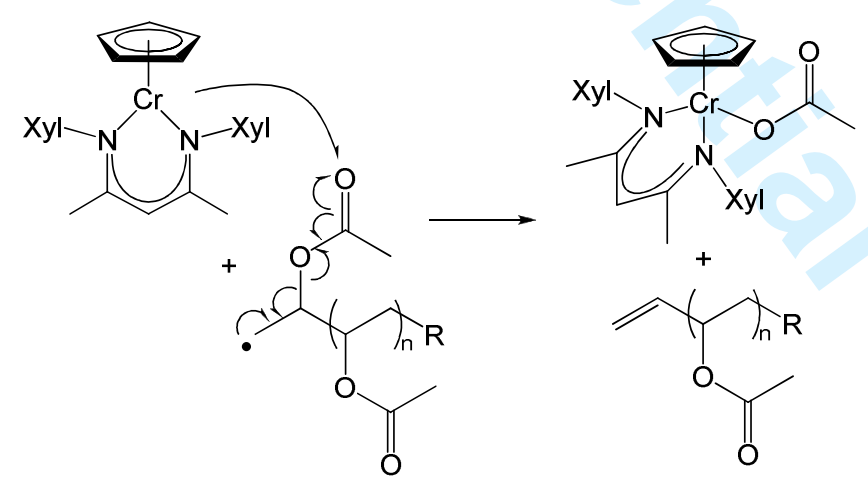

\section{Scheme 4}

\section{Conclusions}


The present study has revealed a more complex situation than previously appreciated for the OMRP of vinyl acetate mediated by half-sandwich $\mathrm{Cr}^{\mathrm{II}}$ complexes of type $\mathrm{CpCr}($ nacnac). The new data reported here confirm the sterical labilization of the $\mathrm{Cr}^{\mathrm{III}}$-PVAc bond, with the more encumbering nacnac ${ }^{\text {dipp,dipp }}$ ligand resulting in a faster apparent rate constant for polymer growth than the nacnac ${ }^{\mathrm{xyl}, \mathrm{xyl}}$ ligand. However, the relatively stronger bond of $\mathrm{Cp}\left(\right.$ nacnac $\left.^{\mathrm{xyl}, \mathrm{xyl}}\right) \mathrm{Cr}-\mathrm{PVAc}$ is still sufficiently labile to sustain the OMRP of vinyl acetate even at room temperature. On the other hand, an irreversible deactivation process comes into play, slowly at room temperature and faster upon warming, to yield a new material now firmly identified as the acetate complex, $\mathrm{CpCr}\left(\right.$ nacnac $\left.^{\mathrm{xyl}, \mathrm{xyl}}\right) \mathrm{OAc}$.

\section{Acknowledgement}

RP thanks the Agence Nationale de la Recherche (contract ANR No. NT05-2_42140) and the Institut Universitaire de France for financial support, and the Centre Interuniversitaire de Calcul de Toulouse (CICT, project CALMIP) for granting free CPU time. KMS thanks the Natural Sciences and Engineering Research Council of Canada (NSERC) for financial support, and thanks Jeffrey A. Therrien and Julia L. Conway for obtaining single crystals of $\mathbf{3}$ and $\mathbf{7}$, respectively, suitable for X-ray diffraction.

Supporting Information Available: A listing of the Cartesian coordinates and final 


\section{References}

Chen, E. Y.-X., Chem. Rev. 2009, 109, 5157-5214.

Williams, B. S.; Leatherman, M. D.; White, P. S.; Brookhart, M., J. Am. Chem. Soc. 2005, 127, 5132-5146.

Berkefeld, A.; Drexler, M.; Möller, H. M.; Mecking, S., J. Am. Chem. Soc. 2009, 131, 12613-12622.

(a) Ito, S.; Munakat, K.; Nakamura, A.; Nozaki, K., J. Am. Chem. Soc. 2009, 131, 14606. (b) Nakamura, A.; Ito, S.; Nozaki, K. Chem. Rev. 2009, 109, 5215-5244.

Satoh, K.; Kamigaito, M., Chem. Rev. 2009, 109, 5120-5156.

Poli, R., Angew. Chem., Int. Ed. Engl. 2006, 45, 5058-5070.

Debuigne, A.; Poli, R.; Jérôme, C.; Jérome, R.; Detrembleur, C., Prog. Polym. Sci. 2009, 34, 211-239.

Smith, K. M., Coord. Chem. Rev. 2006, 250, 1023-1031.

Furstner, A., Chem. Rev. 1999, 99, 991-1046.

Wessjohann, L. A.; Scheid, G., Synthesis 1999, 1-36.

Takai, K.; Nitta, K.; Fujimura, O.; Utimoto, K., J. Org. Chem. 2002, 54, 4732-4734.

Takai, K.; Matsukawa, N.; Takahashi, A.; Fujii, T., Angew. Chem., Int. Ed. Eng. 1998, 37 , 152-155.

Wessjohann, L. A.; Schmidt, G.; Schrekker, H. S., Tetrahedron 2008, 64, 2134-2142.

Doherty, J. C.; Ballem, K. H. D.; Patrick, B. O.; Smith, K. M., Organometallics 2004, 23 , 1487-1489.

MacLeod, K. C.; Conway, J. L.; Tang, L.; Smith, J. J.; Corcoran, L. D.; Ballem, K. H. D.;

Patrick, B. O.; Smith, K. M., Organometallics in press (doi: 10.1021/om900788c).

Champouret, Y.; Baisch, U.; Poli, R.; Tang, L.; Conway, J. L.; Smith, K. M., Angew. Chem., Int. Ed. Engl. 2008, 47, 6069-6072.

Schrock, R. R., Acc. Chem. Res. 1979, 12, 98-104.

Foley, P.; Dicosimo, R.; Whitesides, G. M., J. Am. Chem. Soc. 1980, 102, 6713-6725.

Pamplin, C.; Legzdins, P., Acc. Chem. Res. 2003, 36, 223-233.

Mindiola, D. J., Acc. Chem. Res. 2006, 39, 813-821.

Tsou, T.-T.; Loots, M.; Halpern, J., J. Am. Chem. Soc. 1982, 104, 623-624.

Wayland, B. B.; Poszmik, G.; Mukerjee, S., J. Am. Chem. Soc. 1994, 116, 7943-7944.

Fernandez, I.; Trovitch, R. J.; Lobkovsky, E.; Chirik, P. J., Organometallics 2008, 27, 109-118.

Pangborn, A. B.; Giardello, M. A.; Grubbs, R. H.; Rosen, R. K.; Timmers, F. J., 
Organometallics 1996, 15, 1518-1520.

Armarego, W. L. F.; Perrin, D. D., Purification of Laboratory Chemicals. ed.; Butterworth

Heinemann, 4th ed.: 1996.

Budzelaar, P. H. M.; De Gelder, R.; Gal, A. W., Organometallics 1998, 17, 4121-4123.

Cheng, M.; Moore, D. R.; Reczek, J. J.; Chamberlain, B. M.; Lobkovsky, E. B.; Coates, G. W., J. Am. Chem. Soc. 2001, 123, 8738-8749.

Gong, S. G.; Ma, H. Y., Dalton Trans. 2008, 3345-3357.

Panda, T.; Gamer, M.; Roesky, P., Organometallics 2003, 22, 877-878.

(a) Andersen, R. A.; Wilkinson, G., J. Chem. Soc., Dalton Trans. 1977, 809-811. (b) Dryden, N. H.; Legzdins, P.; Trotter, J.; Yee, V. C., Organometallics 1991, 10, 2857-2870.

Hao, S. K.; Song, J. I.; Berno, P.; Gambarotta, S., Organometallics 1994, 13, 1326-1335.

(a) Baker, M. V.; Field, L. D.; Hambley, T. W. Inorg. Chem. 1988, 27, 2872-2876. (b) Schubert, E. M. J. Chem. Educ. 1992, 69, 62.

SAINT, version 7.03A. ed.; Bruker Analytical X-ray System: Madison, WI, USA, 1997-2003. SADABS. Bruker Nonius area detector scaling and absorption correction - V2.10. ed.; Bruker AXS Inc.: Madison, Wisconsin, USA, 2003.

Altomare, A.; Burla, M.; Camalli, M.; Cascarano, G.; Giacovazzo, C.; Guagliardi, A.; Moliterni, A.; Polidori, G.; Spagna, R., J. Appl. Cryst. 1999, 32, 115-119.

Sheldrick, G. M., SHELXTL, version 5.1. ed.; Bruker AXS, Inc.: Madison WI, 1997.

Farrugia, L. J., J. Appl. Crystallogr. 1997, 32, 565.

Frisch, M. J., et al., Gaussian 03, Revision D.01. ed.; Gaussian, Inc.: Wallingford CT, 2004.

Becke, A. D., J. Chem. Phys. 1993, 98, 5648-5652.

Rappe, A. K.; Casewit, C. J.; Colwell, K. S.; Goddard, W. A.; Skiff, W. M., J. Am. Chem. Soc. 1992, 114, 10024-10035.

Ehlers, A. W.; Boehme, M.; Dapprich, S.; Gobbi, A.; Hoellwarth, A.; Jonas, V.; Koehler, K. F.; Stegmann, R.; Veldkamp, A.; Frenking, G., Chem. Phys. Lett. 1993, 208, 111-114.

Fan, H. J.; Adhikari, D.; Saleh, A. A.; Clark, R. L.; Zuno-Cruz, F. J.; Cabrera, G. S.; Huffman, J. C.; Pink, M.; Mindiola, D. J.; Baik, M. H., J. Am. Chem. Soc. 2008, 130, 17351-17361. Huang, Y. B.; Jin, G. X., Dalton Trans. 2009, 767-769.

Solution phase measurements give the bimolecular rate constant for the reaction of methyl radical with vinyl acetate as $1.4 \times 10^{4} \mathrm{M}^{-1} \mathrm{~s}^{-1}$, while the same reaction with the more stabilized benzyl radical has $k=14 \mathrm{M}^{-1} \mathrm{~s}^{-1}$ : (a) Zytowski, T.; Fischer, H. J. Am. Chem. Soc. 1996, 118, 437-439. (b) Fischer, H.; Radom, L. Angew. Chem. Int. Ed. 2001, 40, 1340-1371.

Hermes, A. R.; Morris, R. J.; Girolami, G. S., Organometallics 1988, 7, 2372-2379.

Mowat, W.; Shortland, A. J.; Hill, N. J.; Wilkinson, G., J. Chem. Soc., Dalton Trans. 1973, 770-778.

Schulzke, C.; Enright, D.; Sugiyama, H.; Leblanc, G.; Gambarotta, S.; Yap, G. P. A.; Thompson, L. K.; Wilson, D. R.; Duchateau, R., Organometallics 2002, 21, 3810-3816.

Meijboom, N.; Schaverien, C. J.; Orpen, A. G., Organometallics 1990, 9, 774-782.

Danopoulos, A. A.; Wilkinson, G.; Sweet, T. K. N.; Hursthouse, M. B., J. Chem. Soc., Dalton Trans. 1995, 2111-2123.

Coles, M. P.; Gibson, V. C.; Clegg, W.; Elsegood, M. R. J.; Porrelli, P. A., J. Chem. Soc., Chem. Commun. 1996, 1963-1964.

The metallacylobutane $\mathrm{Cp} * \mathrm{Cr}$ (pyridine $)\left(\mathrm{CH}_{2}\right)_{2} \mathrm{CMe}_{2}$ has been prepared via the route 
developed for the analogous $\mathrm{CH}_{2} \mathrm{SiMe}_{3}$ reactions: Heintz, R. A.; Leelasubcharoen, S.; Liable-Sands, L. M.; Rheingold, A. L.; Theopold, K. H., Organometallics 1998, 17, 5477-5485. Heinemann, O.; Jolly, P. W.; Krüger, C.; Verhovnik, G. P. J., J. Organometal. Chem. 1998, 553, 477-479.

53 Kim, W.-K.; Fevola, M. J.; Liable-Sands, L. M.; Rheingold, A. L.; Theopold, K. H., Organometallics 1998, 17, 4541-4543. Inorg. Chem. 2001, 1895-1903.

55 Gallant, A. J.; Smith, K. M.; Patrick, B. O., Chem. Commun. 2002, 2914-2915.

56 Poli, R., Chem. Rev. 1996, 96, 2135-2204.

57 Fettinger, J. C.; Mattamana, S. P.; Poli, R.; Rogers, R. D., Organometallics 1996, 15, 4211-4222.

58 Mattamana, S. P.; Poli, R., Organometallics 1997, 16, 2427-2433.

59 De Bruin, B.; Dzik, W. I.; Li, S.; Wayland, B. B., Chem. Eur. J. 2009, 15, 4312-4320. 


\section{Graphical Abstract for Table of Contents}

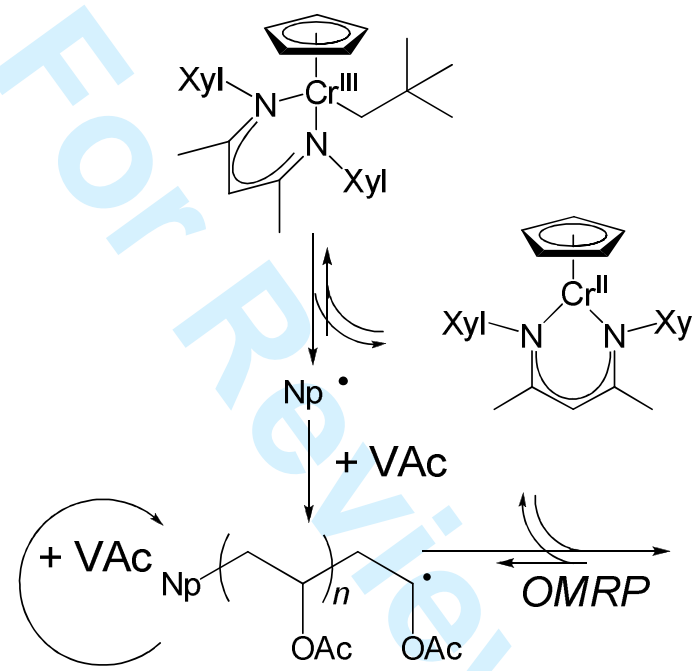

$$
\begin{gathered}
\mathrm{Xyl}=2,6-\mathrm{Me}_{2} \mathrm{C}_{6} \mathrm{H}_{3} \\
\mathrm{~Np}=\mathrm{CH}_{2} \mathrm{CMe}_{3}
\end{gathered}
$$

Symmetric $\mathrm{CpCr}\left[(\mathrm{ArNCMe})_{2} \mathrm{CH}\right]$ complexes $(\mathrm{Ar}=$ 2,6-diisopropylphenyl, 2,6-xylyl,

2,4,6-mesityl or 2,6-diethylphenyl) and a mixed-aryl nacnac complex $\mathrm{CpCr}[\mathrm{ArNC}(\mathrm{Me}) \mathrm{CHC}(\mathrm{Me}) \mathrm{NAr}$ '] (Ar = 2,6-diisopropylphenyl and Ar'= 2,6-xylyl) have been studied as moderators for the polymerization of vinyl acetate initiated by V-70. The isolated, structurally-characterized $\mathrm{Cr}^{\mathrm{III}}$ neopentyl complex $\mathrm{CpCr}\left[(\mathrm{XylNCMe})_{2} \mathrm{CH}\right]\left(\mathrm{CH}_{2} \mathrm{CMe}_{3}\right)$ has been used to polymerize vinyl acetate at room temperature, while elevated temperatures lead to deactivation via formation of the $\mathrm{Cr}^{\mathrm{III}}$ acetate. 